\title{
Tumor necrosis factor $\alpha$ reversibly disrupts the blood-testis barrier and impairs Sertoli-germ cell adhesion in the seminiferous epithelium of adult rat testes
}

\author{
Michelle W M Li ${ }^{*}$, Weiliang Xia ${ }^{*}$, Dolores D Mruk ${ }^{*}$, Claire Q F Wang ${ }^{*}$, Helen H N Yan ${ }^{*}$, Michelle K Y Siu", \\ Wing-yee Lui ${ }^{1}$, Will $M$ Lee $^{1}$ and $C$ Yan Cheng
}

Population Council, 1230 York Avenue, New York 10021, USA

${ }^{1}$ Department of Zoology, The University of Hong Kong, Hong Kong, China

(Requests for offprints should be addressed to C Y Cheng; Email: y-cheng@popcbr.rockefeller.edu)

*(M W M Li, W Xia, D D Mruk, C Q F Wang, H H N Yan and M K Y Siu contributed equally to this work)

\begin{abstract}
The timely restructuring of the blood-testis barrier (BTB) that facilitates the migration of preleptotene and leptotene spermatocytes from the basal to the adluminal compartment in the seminiferous epithelium of adult rat testes, which occurs at late stage VII through early stage VIII of the epithelial cycle, is a crucial cellular event of spermatogenesis. However, the regulation of BTB dynamics at the biochemical level remains elusive. In this study, tumor necrosis factor $\alpha$ (TNF $\alpha$ ), a secretory product of Sertoli and germ cells in rat testes, was shown to affect junction dynamics in vivo. Following an acute administration of recombinant TNF $\alpha$ directly to adult rat testes in vivo at 0.5 and $2 \mu \mathrm{g}$ /testis (with a body weight $\sim 300 \mathrm{~g}$ ), this treatment significantly and transiently disrupted the BTB. It also transiently inhibited the steady-state protein levels of occludin, zonula occludens-1, and $\mathrm{N}$-cadherin, but not junction adhesion molecule-A, $\alpha-$, and $\beta$-catenin in testes at the BTB site as illustrated by immunoblottings, immunohistochemistry, electron
\end{abstract}

microscopy, and fluorescent microscopy. This transient disruption of the BTB integrity induced by TNF $\alpha$ treatment was further demonstrated by a functional test to assess the passage of a fluorescent dye (e.g. fluorescein-5-isothiocyanate) from the systemic circulation to the adluminal compartment. Additionally, both the phosphorylated-Ser/Thr protein kinase activated by MAP kinase kinase (p-p38) and phosphorylated-externally regulated kinase (p-ERK) mitogen -activated protein kinase-signaling pathways were transiently activated. Collectively, these data coupled with the recently published in vitro studies have illustrated that the BTB is likely utilizing a novel mechanism in which localized production of TNF $\alpha$ by Sertoli and germ cells into the microenvironment at the basal compartment facilitates the timely restructuring ('opening'?) of the BTB during spermatogenesis to facilitate germ cell migration.

Journal of Endocrinology (2006) 190, 313-329

\section{Introduction}

In rodent testes, tumor necrosis factor $\alpha$ (TNF $\alpha ; M_{r} 51 \mathrm{kDa}$ consisting of three identical subunits of $17 \mathrm{kDa}$ each) is secreted mostly by germ cells, particularly pachytene spermatocytes and round spermatids, and Sertoli cells and macrophages to some extent; however, its receptors are largely confined to Sertoli cells (De et al. 1993, Skinner 1993, Hedger 2002, Hedger \& Meinhardt 2003, Siu et al. 2003a). $\mathrm{TNF} \alpha$ is a multifunctional cytokine in mammalian testes, regulating different cellular processes pertinent to spermatogenesis. These include steroidogenesis, apoptosis by promoting germ cell survival, function of growth factors (e.g. insulin-like growth factor), follicle-stimulating hormone action, Fas-ligand system, Sertoli cell secretory function and energy metabolism, and inflammatory responses, similar to many of its effects discovered in epithelia from different organs (Mauduit et al. 1993, Magueresse-Battistoni et al. 1995, Besset et al. 1996, Nehar et al. 1997, Sigillo et al. 1999, Pentikainen et al. 2001, Aggarwal 2003, Hedger \& Meinhardt 2003, Vilcek 2003, Bornstein et al. 2004, Hong et al. 2004, Mruk \& Cheng 2004, Suominen et al. 2004, Xia et al. 2005). In addition to these functions that are ascribed to TNF $\alpha$, an earlier study has shown that this pro-inflammatory cytokine may have another crucial role in testicular function related to cell adhesion in the seminiferous epithelium. For instance, chronic administration of TNFa to adult rats in vivo via systemic administration at about $2-4 \times 10^{5}$ units $/ \mathrm{kg}$ body weight (bw) per $24 \mathrm{~h}$ was shown to induce germ cell loss from the seminiferous epithelium, which is likely to be via a yet-to-be defined mechanism at the Sertoli-germ cell interface unrelated to inflammatory responses (Mealy et al. 1990), but 
it was not known at the time if the blood-testis barrier (BTB) was disrupted (Mealy et al. 1990).

Recent in vitro studies have indeed demonstrated that $\mathrm{TNF} \alpha$ is a potential crucial regulator of junction dynamics using Sertoli cells cultured in vitro. For instance, treatment of primary rat Sertoli cell cultures during tight junction (TJ) assembly with TNF $\alpha$ was shown to perturb the Sertoli cell TJ-permeability barrier, concomitant with a drop in the steady-state protein level of occlusion produced by Sertoli cells (Siu et al. 2003a), suggesting that this cytokine may regulate TJ-barrier function via its effects on the levels of $\mathrm{TJ}$-proteins in the testis. TNF $\alpha$ was also shown to inhibit the expression of claudin-11 by mouse Sertoli cells cultured in vitro (Hellani et al. 2000). In light of the effects of TNF $\alpha$ on Sertoli cell TJ-barrier function in vitro, these earlier findings seem to implicate the potential significance of TNFa in BTB dynamics in the testis, since TJ-barrier function at the BTB is contributed largely by the interSertoli cell TJ. Furthermore, Sertoli and germ cells may secrete this cytokine into the microenvironment at the BTB to facilitate the migration of preleptotene and leptotene spermatocytes at late stage VII through stage VIII of the epithelial cycle in adult rat or mouse testes (Russell 1977). This speculation is not proposed without basis. First, studies in other epithelia have shown that $\mathrm{TNF} \alpha$ downregulated occludin in human HT-29/B6 epithelial cells via its effects on the occludin promoter (Mankertz et al. 2000). Secondly, $\mathrm{TNF} \alpha$ was also shown to induce adhesion disruption in epithelial cells via its disruptive effects on the cadherin/ $\beta$ catenin complex and the actin filaments (Tabibzadeh et al. 1995). Thirdly, the localization of TNF $\alpha$ in the seminiferous epithelium in adult rat testes was stage-specific, being the highest at stages VI-early VIII (but not late VIII) at the apical ectoplasmic specialization (apical ES) and the BTB sites (Siu et al. 2003a). Collectively, these data thus suggest that TNF $\alpha$ may be a crucial regulator of junction dynamics in the seminiferous epithelium in vivo.

In this report, we sought to investigate if $\mathrm{TNF} \alpha$ produced locally by Sertoli and/or germ cells into the microenvironment in the seminiferous epithelium during spermatogenesis modulated the steady-state levels of TJ- and/or adherens junction (AJ)-proteins at the BTB, thereby regulating the BTB integrity and possibly Sertoli-germ cell adhesion. Since studies using several in vivo models of $\mathrm{TJ}$ disruption, such as glycerol or cadmium, have shown that a disruption of the TJ-barrier at the BTB can lead to a disruption of Sertoligerm cell adhesion, these findings illustrate cross-talk between $\mathrm{TJ}$ and Sertoli-germ cell AJ in the seminiferous epithelium (Wiebe et al. 1986, 2000, Hew et al. 1993,). Also, it is of interest to investigate if these effects induced by TNF $\alpha$ treatment are reversible. This report represents an initial step to investigate the mechanism utilized by the testis involving cytokines (e.g. $\mathrm{TNF} \alpha$ ) that regulates BTB dynamics pertinent to germ cell migration and junction restructuring in the seminiferous epithelium during spermatogenesis.

\section{Materials and Methods}

Animals

Male Sprague-Dawley rats were purchased from Charles River Laboratories (Kingston, NY, USA). All animals were housed at The Rockefeller University Laboratory Animal Research Center with free access to water and standard chow and under a $12 \mathrm{~h}$ light: $12 \mathrm{~h}$ darkness cycle. The use of animals in this study was approved by the Rockefeller University Animal Care and Use Committee (Protocol numbers: 00111, 03017, and 06018).

Induction of reversible damage to the BTB and Sertoli-germ cell adhesion by TNF $\alpha$ : an in vivo model to study BTB dynamics

This study was performed to assess if adult rat testes use TNF $\alpha$ to regulate BTB dynamics in vivo. Furthermore, results from this study were also used to assess if local administration of TNF $\alpha$ to the testis of adult rats at a concentration consistent with its physiological level intra-testicularly could become an in vivo model to study BTB dynamics. This model apparently should fulfil the following criteria. First, the agent that was used to induce BTB restructuring should preferably be produced locally by Sertoli and/or germ cells in the seminiferous epithelium. Secondly, the agent should be non-cytotoxic to cells in the epithelium at the doses that were effective to induce junction restructuring. Thirdly, the disruptive effects of the compound to the BTB should be reversible. For instance, the disrupted BTB could be resealed once the agent was metabolized or cleared from the host animals. Our postulate is that TNF $\alpha$ is a product of germ and Sertoli cells, and recent in vitro studies have shown that at the doses that were effective to induce reversible Sertoli cell TJ-barrier disruption, TNF $\alpha$ was non-cytotoxic to Sertoli cells (Siu et al. 2003a). As such, this cytokine is a natural regulator of $\mathrm{BTB}$ dynamics in vivo and that local administration of this cytokine to adult rat testes can be developed into a useful in vivo model to study BTB regulation. In short, groups of rats ( $n=3-5$ for each time point) were treated with recombinant human TNF $\alpha$ (Calbiochem, San Diego, CA, USA) using two dosing regimens of either $0.5 \mu \mathrm{g} /$ testis (low dose) or $2 \mu \mathrm{g} /$ testis (acute high dose). Recombinant proteins were dissolved in PBS $(10 \mathrm{mM}$ sodium phosphate, $0 \cdot 15 \mathrm{M}$ $\mathrm{NaCl}, \mathrm{pH} 7 \cdot 4$ at $22{ }^{\circ} \mathrm{C}$ ) to a desired volume, so that the right testis of an adult rat $(\sim 300 \mathrm{~g} \mathrm{bw})$ received $\sim 150 \mu \mathrm{l}$ PBS containing either 0.5 or $2 \mu \mathrm{g}$ TNF $\alpha$; the left testis served as a control and received either PBS (vehicle control) or no treatment (time 0). Recombinant protein was administered using a 27 gauge needle as described (Russell et al. 1987, Wiebe et al. 2000, Lui et al. 2003b, Siu et al. 2005). Thereafter, rats were killed at different checkpoints (i.e. time point at which a specific cellular event occurs; in groups of three to five rats for each checkpoint) to track the kinetics of changes in the BTB and the status of spermatogenesis: (i) time of TNF $\alpha$ injection (time 0), (ii) time of first appearance of BTB 
disruption ( $\sim 7$ h-day 3$)$, (iii) time of first appearance of germ cell loss from the seminiferous epithelium ( $\sim$ days $3-5)$, (iv) time of first appearance of BTB recovery ( $\sim$ days $5-8$ ), and (v) time of germ cell repopulation in the epithelium (days 14-60). Each experiment was repeated three times. In selected experiments, testes were either immediately placed in Bouin's fixative and processed for paraffin sectioning for hematoxylin-eosin staining, or frozen in liquid nitrogen and stored at $-80{ }^{\circ} \mathrm{C}$ until used for either immunohistochemistry or immunoblottings. Since preliminary experiments have illustrated that in rats treated with $500 \mathrm{ng} \mathrm{TNF} \alpha /$ testis, changes detected in the seminiferous epithelium by histological analysis were less pronounced than the high-dose group, results presented in this report were from studies of the high-dose group only. Using paraffin sections stained with hematoxylin-eosin, at least 600 tubules from testes of four rats ( $\sim 150$ tubules were randomly selected from each testis) were scored for damage from each treatment group under a light microscope (Olympus BX40). A tubule that displayed significant germ cell loss from the seminiferous epithelium was scored as a damaged tubule, which was manifested by the presence of greater than ten elongating/elongate/round spermatids and/or spermatocytes in the tubule lumen (tubules at late stage VIII of the epithelial cycle that were clearly visible and readily distinguishable were not scored as damaged tubules) or significant thinning of the seminiferous epithelium cell layer by up to $50 \%$ versus control tubules. Shrinkage in tubule diameter was also scored by comparing the diameter of each tubule ( $\sim 600$ tubules were scored from at least four rats) from treatment groups with control testes. Micrographs were captured using an Olympus DP70 digital camera at $12.5 \mathrm{MPa}$, and printed on Inkjet paper using an Epson 890 Photo Printer for scoring of damaged tubules.

Preparation of samples, immunoblot analysis, and semiquantitative reverse transcriptase ( $R T)-P C R$

Testis samples were prepared in a lysis buffer $(50 \mathrm{mM}$ Tris$\mathrm{HCl}, 0 \cdot 15 \mathrm{M} \mathrm{NaCl}, 1 \% \mathrm{NP}-40$ (Nonidet P-40, an octylphenol-ethylene oxide condensate) (v/v), $1 \mathrm{mM}$ EGTA, $1 \mathrm{mM}$ phenylmethylsulfonyl fluoride, $1 \mu \mathrm{g} / \mathrm{ml}$ leupeptin, $1 \mu \mathrm{g} / \mathrm{ml}$ aprotinin, and $1 \mathrm{mM}$ sodium orthovanadate, $\mathrm{pH} 7 \cdot 4$ at $22{ }^{\circ} \mathrm{C}$ ) as described (Siu et al. 2005). Equal amounts of protein $(\sim 100 \mu \mathrm{g}$ total protein) from each sample within an experimental group were used for immunoblottings. Protein concentrations in samples were estimated by Coomassie Blue dye-binding assay using BSA as a standard (Bradford 1976). All samples within an experimental group were processed in a single experimental session to eliminate interexperimental variations. Primary antibodies used in this report were obtained commercially. Their sources and the dilutions used for different experiments are listed in Table 1. Total RNA from testicular cells were isolated and RT-PCR was performed as previously described (Siu et al. 2003a). Primers used for PCR amplification of different target genes are listed in Table 2 .
Immunofluorescent microscopy, immunohistochemistry, and electron microscopy

Immunofluorescent microscopy was performed as described earlier (Siu et al. 2003b, 2005) to co-localize occludin/zona occludens-1 (ZO-1), junction adhesion molecule-A (JAMA) $/ Z O-1$, and $N$-cadherin/ $\beta$-catenin to the seminiferous epithelium at the BTB using the corresponding specific antibodies (see Table 1). Immunohistochemistry was used to visualize the changes in the localization of occludin following TNF $\alpha$ treatment as described earlier (Siu et al. 2003a). To eliminate interexperimental variations for studies using fluorescent microscopy or immunohistochemistry, all samples within a treatment group were processed simultaneously by placing two to three cross-sections on a single microscopic slide so that a single investigator could process two to four slides altogether in a single experimental session. Electron microscopy was used as described (Siu et al. 2005), which was performed at The Rockefeller University Bio-Imaging Facility to assess damage to the BTB and apical ectoplasmic specialization (ES) in the seminiferous epithelium from adult rats following local administration of TNF $\alpha$ at $2 \mu \mathrm{g} /$ testis by day 3 .

\section{Assessing the BTB integrity}

Earlier studies have shown that a combination of immunoblottings and fluorescent microscopy to co-localize occludin and ZO-1 at the BTB in the rat testes is a reliable approach to monitor BTB integrity (Wong et al. 2004, 2005). For instance, using fluorescent microscopy, occludin (e.g. red fluorescence, labeled with Cy3), and ZO-1 (e.g. green fluorescence, labeled with fluorescein-5-isothiocyanate, FITC) were co-localized to the same site in the seminiferous epithelium consistent with their localization at the BTB, forming an almost continuous and superimposable fluorescence ring at the BTB (Wong et al. 2004). When the BTB was damaged (e.g. following treatment with $\mathrm{CdCl}_{2}$ ), the levels of these two proteins were greatly diminished and the two superimposable fluorescent rings of occludin and ZO-1 became badly disrupted and disorganized at the BTB (Wong et al. 2004). These changes were also coupled with a significant decline in the steady-state protein levels of occludin and ZO-1 monitored by immunoblottings and immunohistochemistry. When these techniques were compared with more tedious functional approaches, such as the use of electron microscopy or micropuncture technique to monitor the diffusion of $\left[{ }^{125} \mathrm{I}\right]-\mathrm{BSA}$ from the systemic circulation (administered via the jugular vein) across the BTB to rete testis fluid and seminiferous tubule fluid (Chung et al. 2001, Wong et al. 2004), it was shown that they could reliably monitor the BTB integrity. As such, the BTB integrity was assessed by immunoblottings, fluorescent microscopy, and immunohistochemistry as reported herein, which was further confirmed by electron microscopy. Additionally, we have also developed an efficient functional approach to monitor the BTB integrity without the need for using a radioactive isotope, 
Table 1 The sources of different antibodies and their dilutions used for different studies in this report

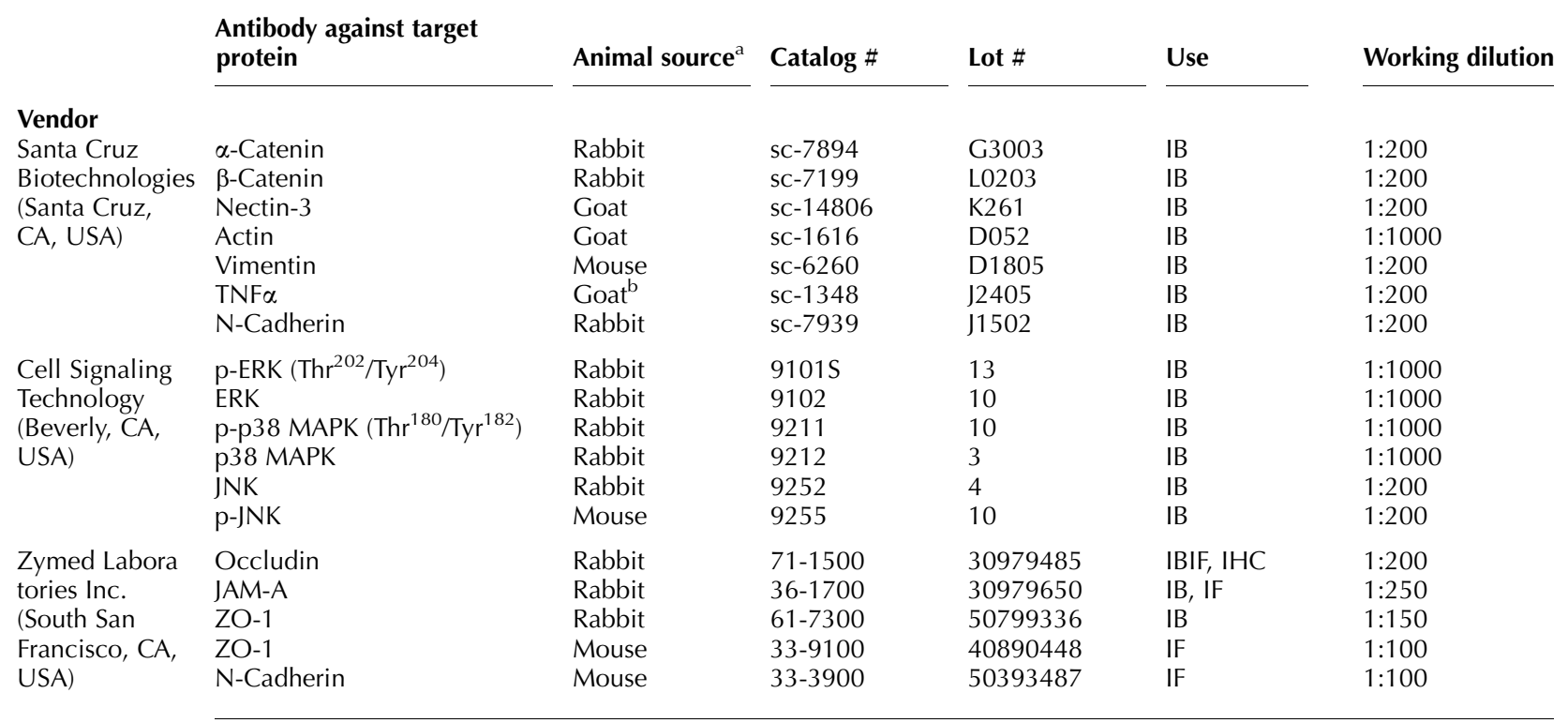

${ }^{a} \mathrm{All}$ antibodies purchased were polyclonal antibodies except for those prepared in mice, which were monoclonal antibodies.

${ }^{\mathrm{b}}$ This anti-TNF $\alpha$ antibody was raised in goat against a fragment of the mouse TNF $\alpha$ from its C-terminus, and it cross-reacted with TNF $\alpha$ of mouse, rat, and human origin by IB as indicated by the vendor. Furthermore, homology search between the primary sequence of the human and rat TNF $\alpha$ proteins using BLAST at GenBank has indicated that they shared $\sim 80 \%$ identity. IB, immunoblotting; IF, immunofluorescent microscopy; IHC, immunohistochemistry.

such as $\left[{ }^{125} \mathrm{I}\right]-\mathrm{BSA}$. In this approach, the diffusion of a fluorescent dye (e.g. FITC) from the systemic circulation to the seminiferous epithelium in treatment groups versus control rats was monitored by fluorescent microscopy. In short, rats following recombinant $\mathrm{TNF} \alpha$ treatment (at $2 \mu \mathrm{g} /$ testis) on days 3 and 10, normal rats (either vehicle control or no treatment, Ctrl), and rats receiving $\mathrm{CdCl}_{2}(3 \mathrm{mg} / \mathrm{kg}$ bw, i.p., on day 3, which is known to disrupt the BTB, to serve as a positive control (Setchell \& Waites 1970, Hew et al. 1993, Wong et al. 2004)) were anesthetized with ketamine $\mathrm{HCl}$ ( 40-60 mg/kg bw, via i.m.) with xylazine $(\sim 10-13 \mathrm{mg} / \mathrm{kg}$, i.m.) as an analgesia. An incision of about $0.5 \mathrm{~cm}$ was made with an Iris scissors over the jugular vein to expose the vessel. Each rat (with two rats for each treatment group including controls) received an infusion of FITC (isomer I, $\mathrm{C}_{21} \mathrm{H}_{11} \mathrm{NO}_{5} \mathrm{~S}, M_{r} 389 \cdot 39$ ) (AnaSpec, Inc., San Jose, CA,
USA) in a final volume of $\sim 200 \mu \mathrm{l}$ (containing $\sim 0.2 \mathrm{mg}$ dissolved in $10 \%$ dimethyl sulphoxide $/ 90 \%$ PBS, v/v) via the jugular vein using a 27 gauge needle. The surgical area was then stitched with nylon suture black monofilament (Ethicon, Inc., Somerville, NJ, USA), cleansed with $70 \%$ ethanol, and the rats allowed to recover. About 90 min thereafter, rats were killed by carbon dioxide asphyxiation, testes were immediately removed, frozen in liquid nitrogen, and frozen sections of $\sim 8 \mu \mathrm{m}$ were cut in a cryostat and examined by an Olympus BX40 microscope equipped with fluorescence optics and an Olympus DP-70 digital camera. The presence of FITC (green fluorescence) in the seminiferous epithelium in treatment groups versus negative (normal rats) and positive $\left(\mathrm{CdCl}_{2}\right.$ treatment) controls were photographed using the built-in digital camera and images acquired with the QCapture Suite (version 2.60, Quantitative Imaging Corp., Burnaby, BC,

Table 2 The nucleotide sequences for primers used for RT-PCR to identify different target genes

\begin{tabular}{|c|c|c|c|c|c|}
\hline & Primer sequence & Orientation & Position & Length (bp) & $\begin{array}{l}\text { GenBank accession \# } \\
\text { or reference }\end{array}$ \\
\hline \multicolumn{6}{|l|}{ Target gene } \\
\hline TNFR2 & $\begin{array}{l}5^{\prime} \text {-GTTCTCTGACACCACATCATCC-3' } \\
5^{\prime} \text {-GTCAATAGGTGCTGCTGTTCAA- } 3^{\prime}\end{array}$ & $\begin{array}{l}\text { Sense } \\
\text { Antisense }\end{array}$ & $\begin{array}{l}579-600 \\
1013-1034\end{array}$ & 456 & AF498039 \\
\hline S-16 & $\begin{array}{l}\text { 5'-TCCGCTGCAGTCCGTT- } \\
\text { CAAGTCTT-3' }\end{array}$ & Sense & $15-38$ & 385 & Chan et al. (1990) \\
\hline
\end{tabular}


Canada) software and examined in Adobe PhotoShop (version 7.0). To eliminate interexperimental variations, all crosssections (about two to three sections per glass slide) from both treatment and control groups were analyzed simultaneously in a single experimental session. Fluorescent images were randomly selected from five different areas per section, photographed, and printed using an Epson 875EX Inkjet printer for examination and scoring. At least 50 tubules from each testis of different treatment groups (e.g. TNF $\alpha$ and $\mathrm{CdCl}_{2}$ ) versus controls (normal testes and testes receiving vehicle) were randomly selected and a total of 100 tubules from two testes of different rats were scored. The distance of the fluorescence (FITC) diffused from the BTB site ( $D_{\text {FITC }}$ ) versus the radius of the seminiferous tubule $\left(D_{\text {radius }}\right)$ were obtained for each tubule in treatment groups and controls, which served as an index to assess the BTB integrity.

\section{Assessing endogenous TNF $\alpha$ levels in adult rat testes}

An efficient solid-phase immunoblot-based assay was developed and used to estimate the endogenous level of TNF $\alpha$ in adult rat testes as follows. In brief, different amounts of recombinant human TNF $\alpha$ (Calbiochem) protein at 1, 3, 5, 10 , and $15 \mathrm{ng}$ were resolved by SDS-PAGE on a $12 \cdot 5 \% \mathrm{~T}$ SDS-polyacrylamide gel under reducing conditions with $\sim 300 \mu \mathrm{g}$ total protein from spent media of Sertoli and germ cells, and lysates of Sertoli cells, germ cells and testes. Each sample was run in duplicates. To eliminate interexperimental variations, all unknowns and standards were resolved onto a single SDS-polyacrylamide gel with one set of samples, and each experimental session routinely consisted of two gels that were processed in the same SDS-PAGE tank. Following electrophoretic transfer of these proteins onto nitrocellulose membranes, the blots were immunostained with an anti$\mathrm{TNF} \alpha$ antibody against mouse TNF $\alpha$, which is known to cross-react with the human and rat TNF $\alpha$ (see Table 1). The resultant blots were then densitometrically scanned at $610 \mathrm{~nm}$ using SigmaGel software (version 1.05; SPSS, Inc., Chicago, IL, USA), and the area of the protein peak corresponding to $\mathrm{TNF} \alpha$ for both standards (i.e. recombinant TNF $\alpha$ ), and lysates of testicular cells and testes were obtained. Data were analyzed using GraFit Data Analysis Software (version 5, Erithacus Software Ltd, Horley, Surrey, UK) using linear regression by plotting the mean area for each of the standards on the $y$-axis against TNF $\alpha(\mathrm{ng})$ on the $x$-axis, and the levels of TNF $\alpha$ in unknowns were interpolated from the resultant curve.

\section{Statistical analysis}

Experiments reported herein were repeated at least three times unless otherwise specified, including all studies using immunohistochemistry, fluorescent microscopy, and immunoblottings. In most morphology studies, experiments were conducted by two different investigators in the laboratory using different sets of treated samples versus controls over a 2 -year period. Data shown herein are representative results of these analyses. Multiple comparisons were performed using ANOVA, followed by Tukey's honestly significant test to compare selected pairs of samples within an experimental group. Statistical analysis was performed using the GB-STAT statistical analysis software package (version 7, Dynamic Microsystems, Inc., Silver Spring, MD, USA).

\section{Results}

\section{$T N F \alpha$ regulates $B T B$ dynamics in adult rat testes}

When recombinant $\mathrm{TNF} \alpha$ was administered to testes of adult rats at $500 \mathrm{ng} /$ testis, a loss of occludin from the BTB was detected by fluorescent microscopy and immunoblottings (data not shown). This loss became much more pronounced when an acute dose at $2 \mu \mathrm{g}$ TNF $\alpha$ was administered per testis (see Fig. 1). As shown in Fig. 1, occludin (a TJ-integral membrane protein) and ZO-1 (a TJ-associated adaptor) were co-localized to the same site at the basal compartment in normal rat testes or testes from rats treated with vehicle only (see Fig. 1A-D) consistent with their localization at the BTB and that these proteins formed an almost continuous belt at the BTB surrounding the entire seminiferous tubule (see Fig. 1A-D). However, both TJ-proteins were greatly reduced by day 3 following TNF $\alpha$ treatment with diminished fluorescence (Fig. 1E-H vs A-D). However, this effect apparently was limited to occludin and ZO-1, since the localization pattern and the fluorescence of JAM-A (also a TJ-integral membrane protein) was not perturbed (Fig. 1I-P vs $\mathrm{A}-\mathrm{H})$. The $\mathrm{TNF} \boldsymbol{\alpha}$-induced damage to the $\mathrm{BTB}$ was further examined by electron microscopy. As shown in Fig. 2A and B, the actin filament bundles and the associated endoplasmic reticulum (ER) at the basal ES that co-exists with TJs at the BTB became severely disorganized and defragmented (see black arrowheads in the boxed area in Fig. 2B) by day 3 after TNF $\alpha$ treatment at a dose of $2 \mu \mathrm{g} /$ testis when compared with normal testes shown in Fig. 2A (see the boxed area showing the typical ultrastructure of the BTB in normal adult rat testes). While TJs in this area (see black arrowheads in Fig. 2B) remained largely unaffected even though the co-existing basal ES was badly damaged, TJs that were found further up of the BTB became severely damaged as manifested by a significant increase in the intercellular space between the two adjacent Sertoli cells and the loss of actin filament bundles and cisternae of ER typical of basal ES (see asterisks in the boxed area in Fig. 2B versus the boxed area in Fig. 2A). Interestingly, this TNF $\alpha$ treatment also induced disruption and/or disorganization of the actin filament bundles and the cisternae of ER at the apical ES (Fig. 2D, E vs C; Fig. 2C is from a normal rat testis showing the typical ultrastructural features of apical ES in which the actin filament bundles were sandwiched between the cisternae of ER and the Sertoli cell plasma membrane, which was restricted only to the Sertoli cell side and not found in elongating spermatids. In the basal 

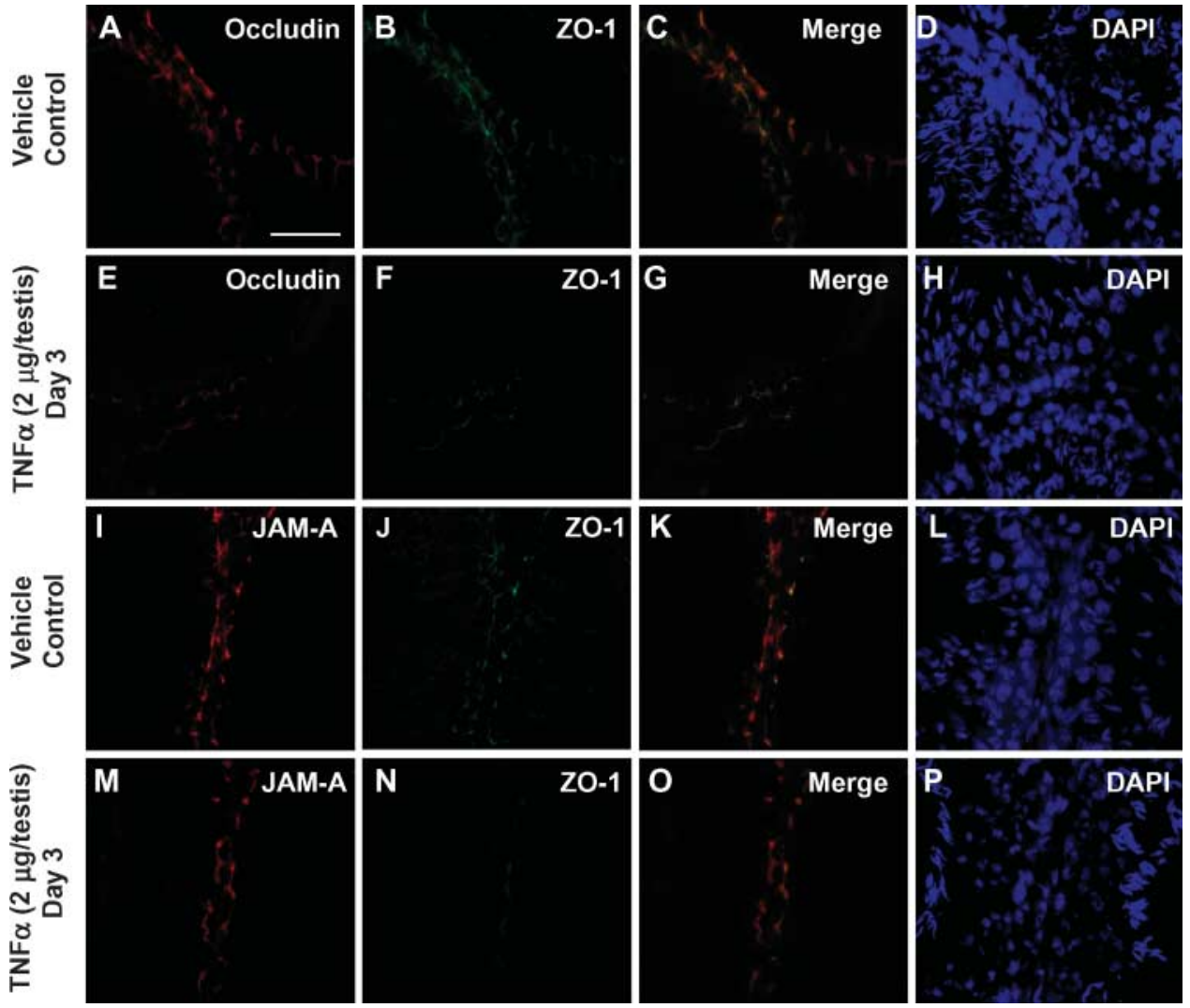

Figure 1 (A)-(P) A study to assess the tumor necrosis factor (TNF) $\alpha$-induced BTB damage by immunoflourescent microscopy. Fluorescent micrographs using cross-sections of frozen testes from rats received vehicle control (A)-(D), (I)-(L), or TNF $\alpha(2 \mu \mathrm{g} /$ testis $)(E)-(H),(M)-(P)$. Rats were killed on day 3 in the treatment groups. Red fluorescence (Cy3) represents occludin, (A) and (E), and JAM-A, (I) and (M), whilst the green fluorescence (FITC) represents ZO-1, (B), (F), (J), and $(N)$. The merged micrographs $(C),(G),(K)$, and $(\mathrm{O})$ illustrate the co-localization of occludin and ZO-1 (A)-(H) or JAM-A and ZO-1 (I)-(P) to the same site in the basal compartment, consistent with their localization at the BTB, which appears as orange fluorescence. (D), (H), (L), and (P) are 4'-6-diamidino-2-phenylindole stained for nuclei. In testes receiving vehicle control, occludin, ZO-1, and JAM-1 were found at the BTB forming a continuous fluorescent belt at the basal compartment, (A), (B) and (I), (J). On day 3, the occludin and ZO-1 (E), (F) vs (A), (B); (N) vs (J), but not JAM-A (M) vs (I) fluorescence was greatly reduced. Bar in $A=80 \mu \mathrm{m}$, which also applies to (B)-(P). These fluorescent micrographs are the representative result of one experiment, two additional experiments using sections from different animals yielded similar results.

ES, this feature was found in both sides of the two Sertoli cells, see Fig. 2C vs A). The apical ES is a testis-specific, cell-cell actin-based hybrid AJ and focal contact junction type (Siu \& Cheng 2004) as seen in Fig. 2D and E between an elongating spermatid and Sertoli cell in the seminiferous epithelium.

\section{TNF $\alpha$ affects Sertoli-germ cell adhesion in the seminiferous epithelium}

The status of spermatogenesis in the TNF $\boldsymbol{\alpha}$-treated animals was further examined using hematoxylin-eosin-stained paraffin sections at selected time points and compared with controls (rats received either vehicle control or no treatment) as shown in Fig. 3. It was noted that by day 3 after TNF $\alpha$
( $2 \mu \mathrm{g} /$ testis) treatment, about $15 \%$ of the tubules scored from a total of 600 tubules from four different rats displayed signs of damage as manifested by the appearance of spermatids (elongating and round spermatids) and spermatocytes in the tubule lumen and the thinning of the cell layer in the seminiferous epithelium (Fig. 3A vs B-D). By day 5, over 30\% of the tubules were damaged (Fig. 3E-G), which was accompanied by a significant shrinkage in tubular diameter (Fig. 3G). Thus, these data (Fig. 3B-F vs A) are in agreement with results of the electron microscopy that have illustrated a disruption of the apical ES (see Fig. 2D and E vs C), suggesting that $\mathrm{TNF} \alpha$ treatment perturbed Sertoli-germ cell adhesion in the seminiferous epithelium in particular at the apical ES. Since some spermatocytes and early round spermatids were also depleted from the epithelium (see Fig. 3C and D) 
and the anchoring junctions between these germ cells and Sertoli cells are largely desmosome-like junctions without apical ES, this suggests that TNF $\alpha$ may have a generalized effect on Sertoli-germ cell adhesion. However, the fact that spermatogenesis could be recovered thereafter and the amount of TNF $\alpha$ administered was within the physiological range (see below), suggests that these effects are not the result of cytotoxicity.

\section{Occludin is one of the target proteins of TNF $\alpha$ in the seminiferous} epithelium

To further verify the results of fluorescent microscopy shown in Fig. 1 that occludin is likely a target protein of TNF $\alpha$ induced BTB damage, immunohistochemistry was performed. It was noted that in normal adult rat testes, occludin was restricted to the basal compartment consistent with its localization at the BTB in almost all tubules except for stage VIII tubule (see reddish-brown precipitates in Fig. 4A and B) at the time when preleptotene and leptotene spermatocytes must traverse the BTB, entering the adluminal compartment for further development (Russell 1977). Results reported in Fig. 4 also illustrate that the localization of occludin in the seminiferous epithelium is stage-specific, being the lowest at stage VIII tubules in adult rat testes. Following TNF $\alpha$ treatment $(2 \mu \mathrm{g} /$ testis $)$ on day 3 , the amount of immunoreactive occludin at the BTB was greatly diminished (Fig. 4C and $\mathrm{D}$ vs $\mathrm{A}$ and $\mathrm{B}$ ). Figure $4 \mathrm{E}$ was a control staining using normal rabbit IgG in substitution of the primary antibody. Immunoblottings were subsequently used to validate changes in the occludin protein level and the possible downstream signaling pathways utilized by TNF $\alpha$ to perturb BTB integrity and Sertoli-germ cell adhesion in the seminiferous epithelium. As shown in Fig. 5A (upper panel), the TNF $\alpha-$ induced BTB damage was associated with a transient loss of occludin, ZO-1, and N-cadherin, but not JAM-A, claudin$11, \alpha-$, and $\beta$-catenin (Fig. 5A, B-a, B-b), consistent with results shown in Fig. 1-3. Since earlier studies have shown that transforming growth factor $\beta 3$ (TGF- $\beta 3$ ), another crucial regulator of $\mathrm{BTB}$ dynamics in the testis, modulates $\mathrm{BTB}$ dynamics via the Ser/Thr protein kinase (p38) activated by mitogen-activated protein kinase (MAPK)-signaling pathway (Lui et al. 2003b, Wong et al. 2004), but TGF- $\beta 3$ can also limit its effects on Sertoli-germ cell adhesion via the externally regulated kinase (ERK) MAPK-signaling pathway (Xia \& Cheng 2005), we thus sought to examine if TNF $\alpha$ is utilizing similar mechanism. Indeed, the TNF $\alpha$-induced BTB damage and Sertoli-germ cell adhesion disruption were associated with a transient induction in phosphorylated (p)-p38 MAPK and phosphorylated (p)-ERK, but not phosphorylated (p)-C-Jun N-terminal protein kinase (JNK) (Fig. 5A, middle panel and B-c). The lower panel in Fig. 5A shows the steady-state protein levels of vimentin and $\beta$-actin, which served as loading controls.
TNF $\alpha$-induced BTB damage and Sertoli-germ cell AJ disruption is reversible

Since immunoblot studies have suggested that the significant decline of occludin, $\mathrm{ZO}-1$, and $\mathrm{N}$-cadherin in the testis following TNF $\alpha$ treatment ( $2 \mu \mathrm{g} /$ testis) was reversible, as these proteins rebound by day 8 (see Fig. 5), we sought to examine if their losses at the BTB were indeed transient and reversible. Consistent with the immunoblotting data shown in Fig. 5, a significant loss of fluorescence of occludin and ZO-1 (Fig. 6A, e-h vs a-d) was detected at the BTB site in the seminiferous epithelium as early as 7-h post-TNFa treatment. Yet this loss fully recovered by day 8 , making the fluorescent staining almost indistinguishable from normal testes or testes receiving vehicle control (Fig. $6 \mathrm{~A}, \mathrm{i}-1$ vs a-d and $\mathrm{e}-\mathrm{h}$ ). Similar results were obtained where the loss of $\mathrm{N}$-cadherin from the BTB was also transient as shown in Fig. 6A ( $\mathrm{q}-\mathrm{t}$ vs $\mathrm{m}-\mathrm{p}$ and $\mathrm{u}-\mathrm{x}$ ). These results seemingly suggest that if TNF $\alpha$ can indeed be produced in the microenvironment at the site of $\mathrm{BTB}$, where preleptotene and leptotene spermatocytes are traversing the BTB, this cytokine likely disrupts the BTB transiently to facilitate germ cell migration. Indeed, consistent with an earlier report (De Cesaris et al. 1999), both the p55 TNF $\alpha$ receptor (TNFR1) and $\mathrm{p} 75 \mathrm{TNF} \alpha$ receptor (TNFR2) were shown to be predominantly expressed by Sertoli cells (Fig. 6B). Since TNF $\alpha$ is a product of both germ and Sertoli cells (De et al. 1993, Siu et al. 2003a), it is likely that these testicular cells release TNF $\alpha$ into the microenvironment to facilitate germ cell migration at late stages VII and VIII of the epithelial cycle by temporarily reducing the occludin, $\mathrm{ZO}-1$, and $\mathrm{N}$-cadherin levels, thereby transiently 'opening' the BTB. Using a solid-phase immunoblot-based assay (Fig. 6C), it was shown that germ cells appeared to contribute most of the TNF $\alpha$ in the seminiferous epithelium. The level of TNF $\alpha$ produced by Sertoli cells might be too low to be detected by this method because of its sensitivity, which is $\sim 3 \mathrm{ng}$ (see Fig. 6C) and the loading capacity of an SDS-slab gel $(\sim 300 \mu \mathrm{g}$ protein per lane). Nonetheless, using this solidphase immunoblot-based assay as described in Materials and Methods, it was estimated that an adult rat testis contained $\sim 0 \cdot 5 \pm 0 \cdot 15 \mu \mathrm{g} \mathrm{TNF} \alpha(n=6)$. This also illustrates that the amount of TNF $\alpha$ that was administered per testis at $2 \mu \mathrm{g}$ as reported here is still the likely physiological range in the microenvironment in the testis.

\section{Functional test for assessing the BTB integrity following $T N F \alpha$ treatment}

The BTB integrity was further assessed by a functional test by monitoring the diffusion of FITC (Mr 389) from the systemic circulation to the seminiferous epithelium as described in Materials and Methods. It was shown that treatment of testes with $\mathrm{TNF} \alpha$ at $2 \mu \mathrm{g} /$ testis indeed induced reversible damage to the BTB (Fig. 7F, G vs $\mathrm{H}$, I, and A-C) with $\mathrm{CdCl}_{2}$ that 
served as a positive control (Fig. 7D and E). For instance, FITC was shown to diffuse into the adluminal compartment by day 3 following TNF $\alpha$ treatment, away from the BTB, which is in sharp contrast to control testes in which the FITC fluorescence was limited to the BTB (Fig. 7F, G vs A-C). However, this transient loss of BTB integrity was reversed by day 10 (Fig. 7H-J) versus controls (Fig. 7A-C, J), consistent with the data shown in Fig. 6.
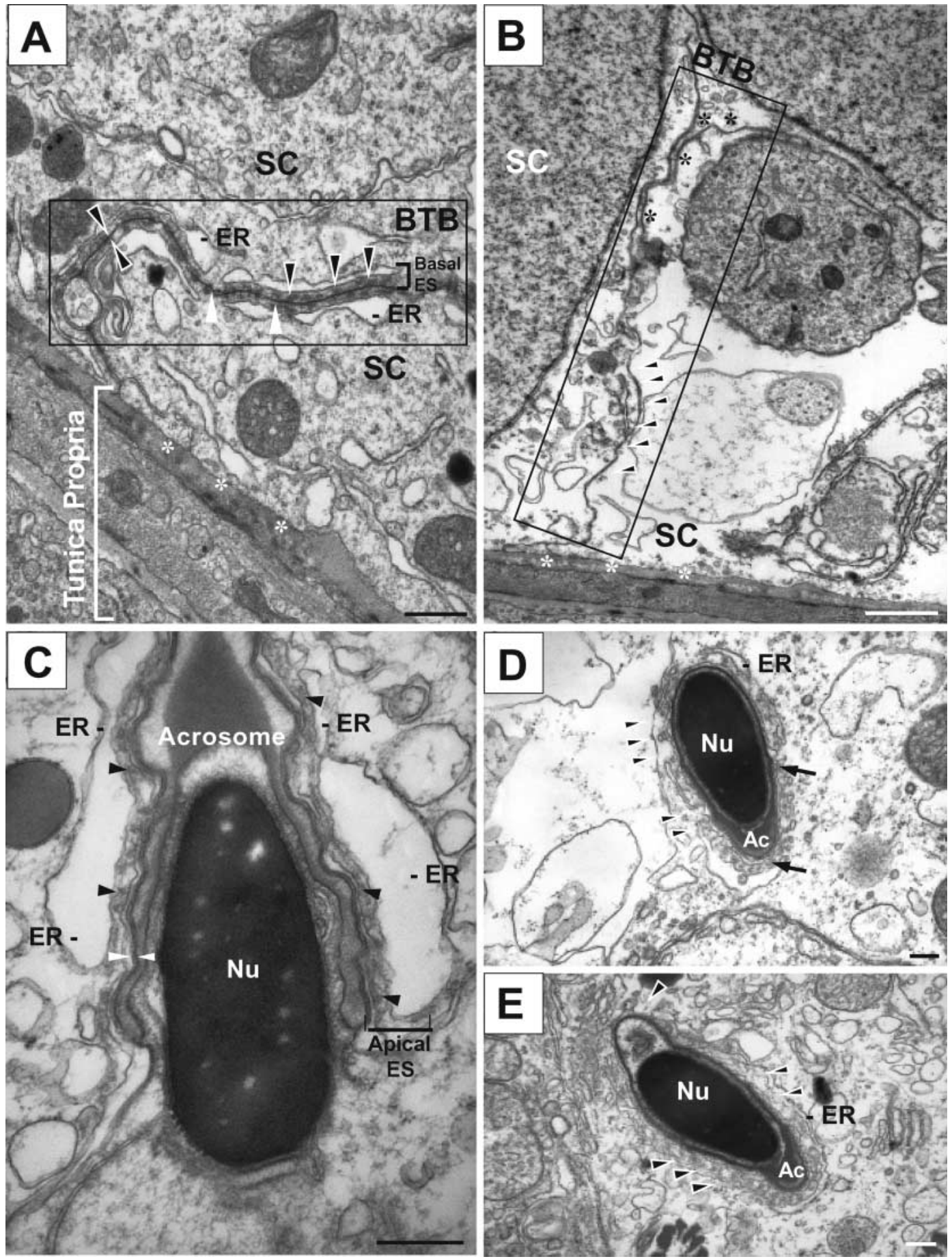


\section{Discussion}

$T N F \alpha$ affects BTB dynamics in the seminiferous epithelium of adult rat testes

Earlier in vitro and in vivo studies have implicated the role of cytokines (e.g. TNF $\alpha$ and TGF- $\beta 3$ ) (Hellani et al. 2000, Lui et al. 2003a, 2003b, Wong et al. 2004, Xia \& Cheng 2005) in Sertoli cell TJ-dynamics, since they were shown to regulate the steady-state levels of TJ proteins, such as claudins, occludins, and $\mathrm{ZO}-1$, at the BTB site in adult rat testes. However, these earlier reports were based on studies using in vivo models, where animals were treated with environmental toxicants (e.g. $\mathrm{CdCl}_{2}$ ) to induce rapid BTB restructuring or they were in vitro in nature using primary Sertoli cell cultures to induce TJ-barrier assembly, so that changes in different target proteins and their regulation can be monitored and assessed. As such, the physiological relevance of earlier studies that implicate $\mathrm{TNF} \alpha$ as a potential regulator of BTB dynamics during spermatogenesis in vivo remains to be established.

We report herein that local administration of TNF $\alpha$ to adult rat testes at a concentration approximately fourfold of the endogenous TNF $\alpha$ level in the testis indeed regulated the steady-state levels of several proteins at the BTB in adult rat testes including occludin, ZO-1, and N-cadherin, inducing transient disruption of the BTB integrity. Collectively, the data presented in this report have helped to formulate a working hypothesis (see Fig. 8) suggesting that at the time preleptotene and leptotene spermatocytes are traversing the BTB at stages VII-VIII of the epithelial cycle, these spermatocytes likely coordinate with Sertoli cells to secrete TNF $\alpha$ to the microenvironment at the BTB in the seminiferous epithelium. TNF $\alpha$ exerts its effects via either one or both of its receptors, TNFR1 and TNFR2, residing on Sertoli cells. This, in turn, activates the p38 MAPK-signaling pathway downstream to 'open' (or disassemble?) the BTB to facilitate preleptotene/ leptotene spermatocyte movement across the barrier, such as by reducing the steady-state levels of occludin and ZO-1 at the BTB. Since this effect is transient, the temporarily 'opened' BTB can be rapidly 'resealed' to maintain the immunological barrier function of the BTB as illustrated in the results reported herein. TNF $\alpha$ can also exert its effects on apical ES via an activation of the ERK-signaling pathway, plausibly facilitating the release of spermatids at spermiation, which also takes place at stage VIII of the epithelial cycle. As such, TNF $\alpha$ is working in concert with other cytokines (e.g. TGF- $\beta 3$ ) to serve a dual function in the seminiferous epithelium by facilitating spermiation and preleptotene/leptotene spermatocyte movement across the BTB at stage VIII of the epithelial cycle. This possibility is strengthened by a recent immunohistochemistry study that has localized TNF $\alpha$ to the basal compartment of the seminiferous epithelium consistent with its localization at the BTB, and to the apical ES predominantly at stages VII through early stage VIII of the epithelial cycle prior to spermiation in adult rat testes (Siu et al. 2003a). We have attempted to perform a similar immunohistochemistry study with the available antiTNR1 and anti-TNFR2 receptor antibodies from two different vendors, but without success because of the low antibody titer and specificity issue. However, an earlier study using an experimental autoimmune orchitis model has illustrated the presence of TNFR 1 in adult rat testes by immunohistochemistry, but it was not reported if TNFR 1 was expressed stage specifically (Suescun et al. 2003). Undoubtedly, a detailed study to localize TNFR1 and TNFR2 in normal testes and their changes during TNF $\alpha$-induced seminiferous tubular damage should be conducted in future studies.

It must be noted that the hypothesis outlined in Fig. 8 should be viewed as a working model, since much research is needed to validate different possibilities. It must also be understood that the hypothesis depicted in Fig. 8 will be rapidly updated as more data become available in the field. This hypothesis somehow serves as a framework upon which functional experiments can be designed. In this context, it is of interest to note that while acute administration of TNF $\alpha$ disrupts the BTB integrity in virtually all the tubules examined, which is consistent with the immunoblotting data, its effects in inducing germ cell loss from the epithelium are limited to only $\sim 30 \%$ of the tubules scored by day 5 after its administration in three separate experiments, suggesting that other cytokines and/or proteins/peptides/factors are also involved in regulating Sertoli-germ cell adhesion in the seminiferous epithelium. Alternatively, TNF $\alpha$ may affect only

Figure 2 (A)-(E) A study by electron microscopy assessing damage to the BTB and apical ES following TNF $\alpha$ treatment. EM micrographs of testes from rats that received vehicle control. The BTB is shown in the boxed area in (A), which is typified by the presence of basal ES (manifested by the presence of actin filament bundles (see black arrowheads) sandwiched between the endoplasmic reticulum (ER) and Sertoli cell (SC) plasma membrane found on both sides of the two apposing SC (see apposing black arrowheads) that co-exist with tight junctions (TJ, see white arrowheads)). The seminiferous epithelium composed of Sertoli and germ cells rests on the basement membrane (asterisks), which is part of the tunica propria. On day 3 after TNF $\alpha$ treatment ( $2 \mu \mathrm{g} /$ testis), the BTB was damaged (B), which was manifested by the disappearance of the basal ES where the actin filaments apparently were disintegrated and the ER also became disorganized (see black arrowheads in (B) vs (A)). The TJ apparently remained largely intact near the basement membrane (white asterisks); however, the TJ seen was broken since the intercellular space was significantly widened between the two adjacent Sertoli cell plasma membranes (see black asterisks in (B)). (C) EM micrograph illustrating the apical ES found between a developing spermatid ( $\mathrm{Nu}$, nucleus) and SC, which is typified by the presence of actin filament bundles (black arrowheads) sandwiched between ER and the SC plasma membrane (the two opposing white arrowheads represent the apposing SC and spermatid plasma membranes). However, on day 3 after TNF $\alpha$ treatment ( $2 \mu \mathrm{g} /$ testis), the apical ES found between an elongating spermatid and Sertoli cells as shown in (D) and (E) also became damaged, as manifested by the disintegration (and disappearance) of actin filament bundles (see black arrowheads) and the loss of ER (see (D), (E) vs (C)) except that in some areas, the actin filament bundles were still seen (see arrowheads in (D)). Ac, acrosome. Bar in $A=0 \cdot 5 \mu \mathrm{m} ; B=1 \mu \mathrm{m} ; C=0 \cdot 2 \mu \mathrm{m}$, which applies to (D) and (E). These micrographs are the representative result of one experiment with two rats for each time point including controls. 

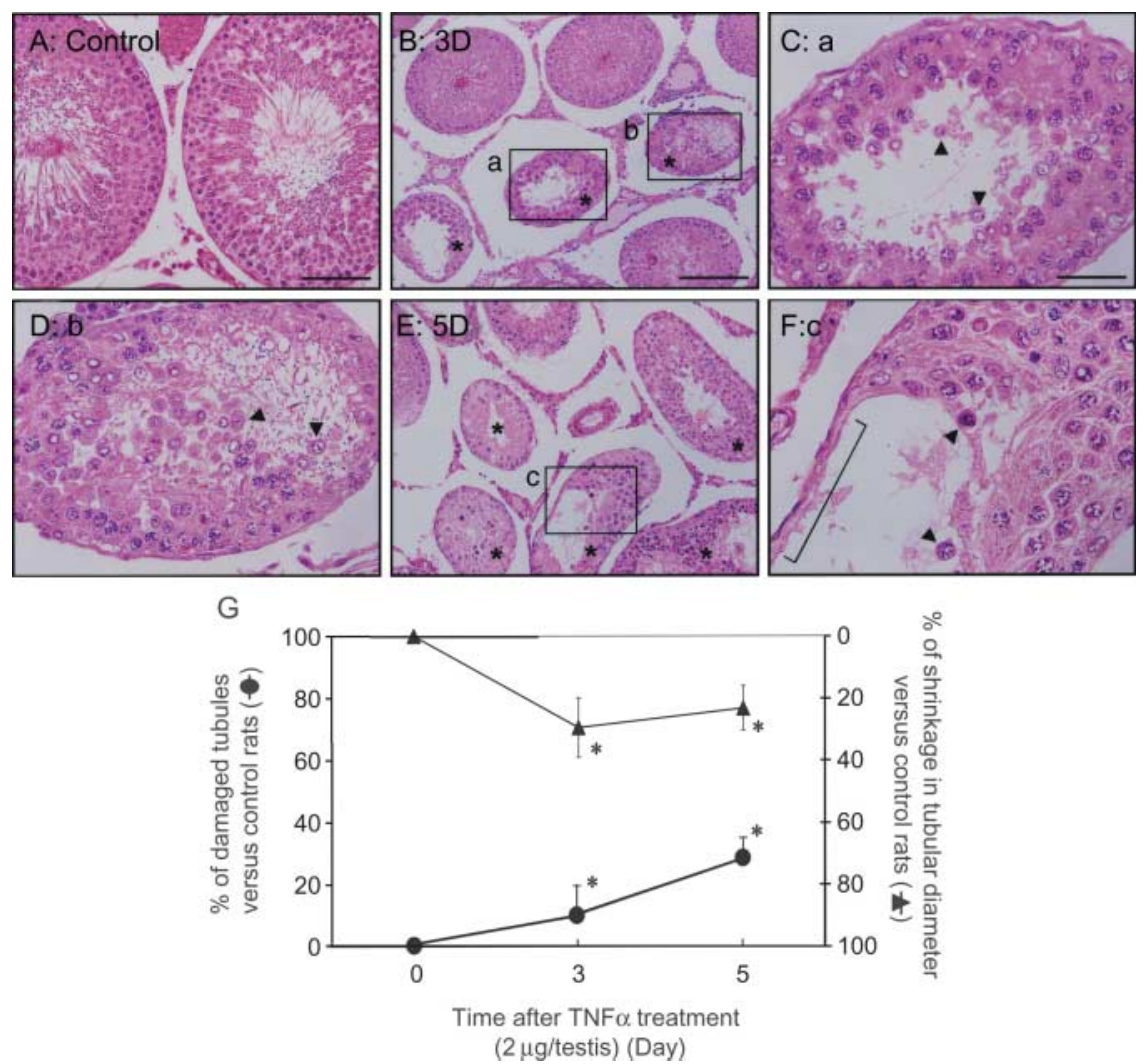

Figure 3 (A)-(G) A study to assess the effects of TNF $\alpha$ treatment $(2 \mu \mathrm{g} /$ testis $)$ on the status of spermatogenesis in adult rat testes. (A)- $(\mathrm{F})$ Micrographs of normal rat testes $(\mathrm{A})$, rat testes after treatment with TNF $\alpha$ on day $3(\mathrm{~B}),(\mathrm{C})$ and $(\mathrm{D})$, and day $5(\mathrm{E})$ and $(\mathrm{F})$. The boxed areas $(\mathrm{a}, \mathrm{b})$ shown in (B) were magnified and shown as (C) and (D) respectively. The boxed area (C) in (E) was also magnified and shown as (F). Asterisk $(*)$ indicates representative damaged tubules with either spermatids spermatocytes found in the tubule lumen (see arrowheads in (C), (D) and (F)) or significant thinning in the seminiferous epithelium (see bracket in (F)). Bar in $A=60 \mu \mathrm{m} ; B=120 \mu \mathrm{m}$, which applies to (E); $C=30 \mu \mathrm{m}$, which applies to $(\mathrm{D})$ and $(\mathrm{F})$. These micrographs are the representative results of one experiment, three other experiments using different cross-sections of testes yielded similar observations. (G) This bar graph summarizes results of analysis by scoring the damaged tubules and changes in tubule diameter following treatment of rats with TNF $\propto$ versus controls $(n=3-5$ rats for each time point). *Significantly different; $P<0 \cdot 05$.

'selected' tubules stage specifically. As such, future studies should include a detailed morphometric analysis to determine whether the TNF $\boldsymbol{\alpha}$-induced seminiferous tubule damage is stage-specific and if Sertoli cells are more susceptible to the TNF $\alpha$-induced damage at stages VII-VIII of the epithelial cycle. Also, a testis-specific knockout of TNF $\alpha$ study in mice will address some important issues pertinent to the precise role of TNF $\alpha$ in junction dynamics.

Additionally, it is of interest to note that Russell \& Peterson (1985) and Russell (1993) have suggested that preleptotene spermatocytes were assimilated into the adluminal compartment by initially constructing new TJs below these cells, to be followed by a dissolution of the 'original' TJs above them at stages VII-VIII in the 'zipper theory'. It seems that TNF $\alpha$ (and other cytokines) plays a role in disrupting the 'original' TJs, yet it has no effects on the 'newly formed' TJs. It can be seen that $T N F \alpha$ exerts its effects only locally by limiting its effects to a specific microenvironment. Alternatively, the 'newly formed' TJs are being protected from TNF $\alpha$ via a yetto-be defined mechanism. These possibilities must be carefully evaluated in future studies.

\section{Issue on changes in target protein levels during $T N F \alpha$-induced $B T B$ restructuring}

During the TNF $\alpha$-induced restructuring in the seminiferous epithelium, we have detected changes in the steady-state levels of several target proteins, such as a transient but significant reduction of occludin, $\mathrm{ZO}-1$, and $\mathrm{N}$-cadherin, but not JAM-A, claudin-11, $\alpha$-, and $\beta$-catenin using lysates from these testes. Since the cellular composition in the seminiferous epithelium underwent extensive changes because of the 

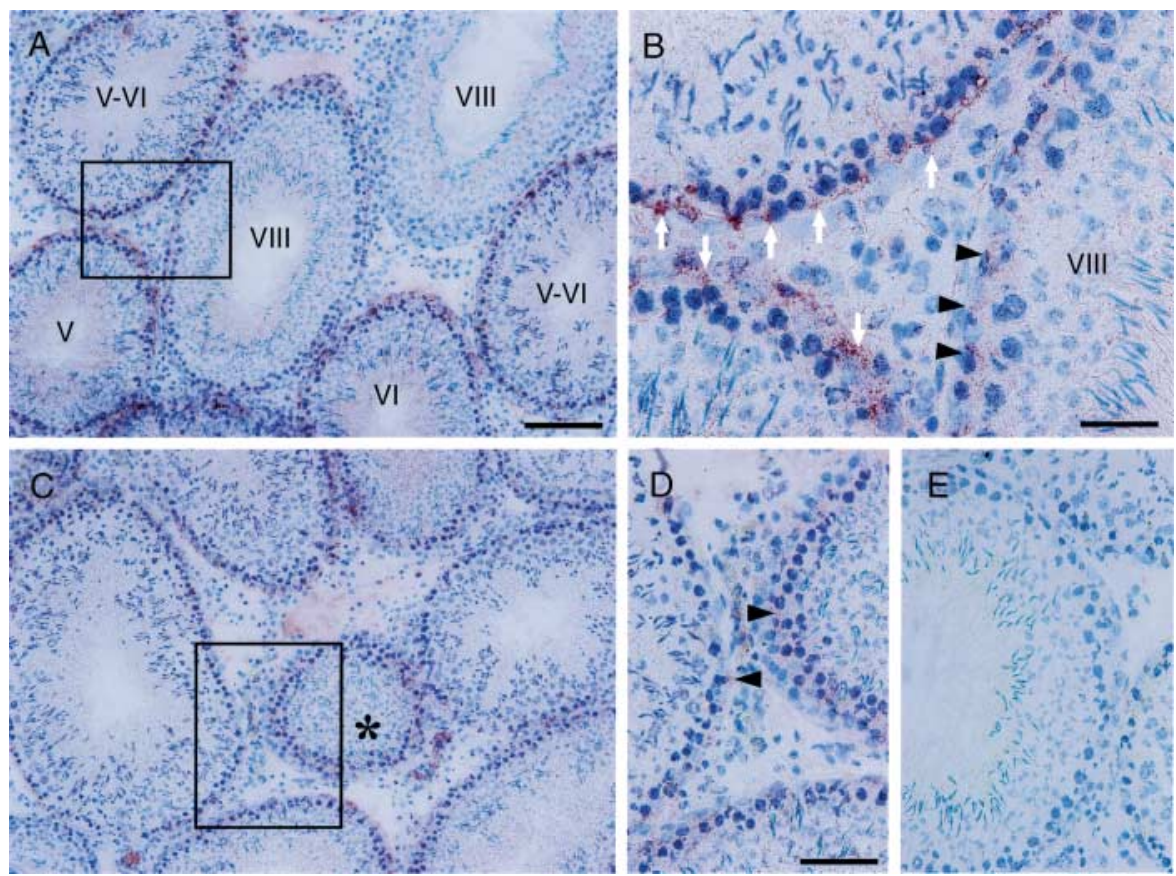

Figure 4 (A)-(E) A study by immunohistochemistry to assess the disappearance of occludin from the BTB site following TNF $\alpha$ treatment ( $2 \mu \mathrm{g} /$ testis). Micrographs using frozen sections of testes for immunohistochemistry to localize occludin in the seminiferous epithelium. In control (normal rat) testes, occludin appears as reddish-brown precipitates confined largely to the basal compartment, consistent with its localization at the BTB (see also Fig. 2). The boxed area in (A) was magnified in (B) and immunoreactive occludin (see white arrows) forms an almost continuous ring at the BTB surrounding the entire tubule at the basal compartment except at stage VIII (see black arrowheads) when preleptotene and leptotene spermatocytes were known to traverse the BTB (Russell 1977). However, on day 3 after TNF $\alpha$ treatment, there was a loss of occludin in the seminiferous epithelium (C), as manifested by the disappearance of occludin from the BTB (see (D), which is the magnified view of the boxed area shown in (C), the arrowheads illustrate the drastic reduction of occulin at the BTB site). (E) is a control in which the primary anti-occludin antibody was substituted by normal rabbit IgG. These immunohistochemistry data are derived from a single experiment, two additional experiments using testes from different animals yielded similar observations. Bar in $A=60 \mu \mathrm{m}$, which applies to $C ; B=15 \mu \mathrm{m} ; \mathrm{D}=30 \mu \mathrm{m}$, which applies to $\mathrm{E}$.

TNF $\alpha$-induced germ cell loss and BTB restructuring, the relative contribution of proteins by Sertoli and germ cells in the lysates would be altered in the time course experiments, such as reported in Fig. 5, negating the significance, perhaps the validity, of these findings. We offer the following explanations to address this important issue.

First, it must be noted that the target proteins that displayed changes in their steady-state levels, such as occludin and ZO-1, were restricted exclusively to Sertoli cells in the seminiferous epithelium. In testis samples that were being analyzed by $7 \mathrm{~h}-3$ days, the lysates contributed to a wider margin by Sertoli cells since germ cells began to deplete from the epithelium at this time, thus one would expect a surge in occludin and ZO-1. Instead, a significant decline was detected. This, in turn, suggests that the 'actual' loss of occludin and ZO-1 could have been more significant. Yet, by day 8 , the levels of occludin bounced back, this also suggests that there was an enhanced production of occludin and $\mathrm{ZO}-1$ by Sertoli cells at this time. We did not attempt to correlate the changes in target protein levels and the alteration of cellular composition since the present technology could not allow us to do so as yet. However, it is obvious that by $7 \mathrm{~h}-3$ days following TNF $\alpha$ treatment, when germ cells were depleting from the epithelium, the relative contribution of Sertoli and germ cells in the lysates being analyzed was not different from rats at time 0 (or other normal rat testes), since many of the dislodged germ cells were still present in the tubule lumen. This logic is applicable to the changes that were detected in p-ERK1/2 and p-p38 MAPK; it also applies to other target proteins, such as $\mathrm{N}$-cadherin and catenins, when they are products of both Sertoli and germ cells at least in these early time points.

Secondly, because of the issue mentioned above, it is crucial that any changes in a target protein should be confirmed with other approaches besides immunoblotting. For instance, the transient loss of occludin during TNF $\alpha$-induced restructuring in the seminiferous epithelium was confirmed by immunohistochemistry, immunofluorescent microscopy, and 

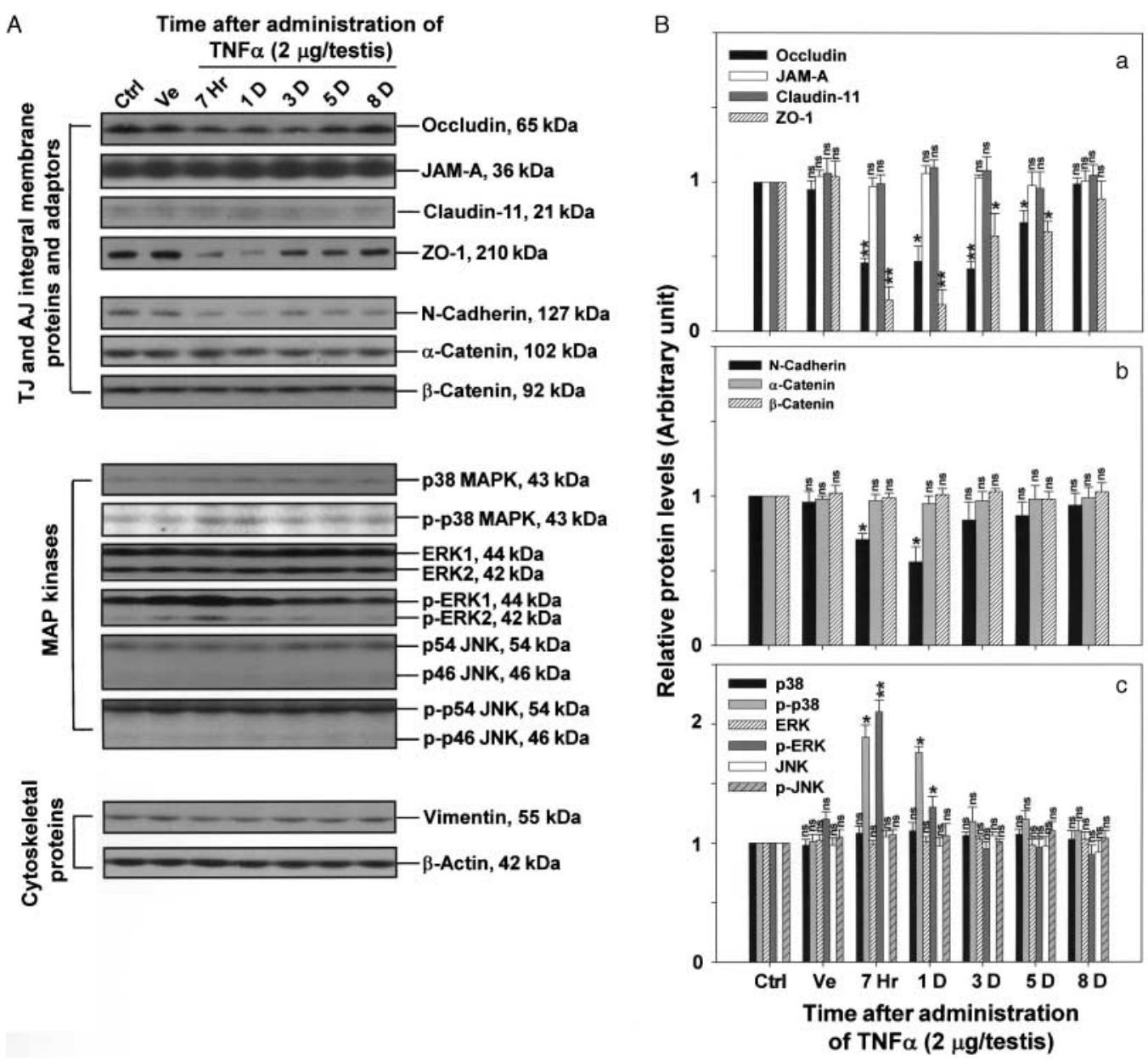

Figure 5 (A) and (B) A study to assess the steady-state levels of different target proteins during TNF $\alpha$-induced BTB restructuring in adult rat testes. Rats were treated with recombinant TNF $\alpha$ (2 $\mu \mathrm{g} /$ testis) via local administration as described in Materials and Methods. (A) Lysates were prepared for immunoblottings to quantify the levels of different TJ- and AJ-proteins and their adaptors (top panel; a and b in (B)), MAP kinases (middle panel; $c$ in (B)), and cytoskeletal proteins (bottom panel). (B) Histograms using data, such as those shown in (A), densitometrically scanned and normalized against $\beta$-actin, plotted where the target protein levels in normal testes (Ctrl) were arbitrarily set at 1 with $n=3-4$ for each sample from at least two sets of experiments. Ve, rats treated with vehicle control and killed on day $3 ; \mathrm{Hr}$, hour; D, day. n.s., not significantly different by ANOVA; $* P<0 \cdot 05 ;{ }^{\dagger} P<0 \cdot 01$.

a functional test to assess BTB integrity. Collectively, these multiple approaches can accurately assess changes of selected target proteins during TNF $\alpha$-induced damage to the BTB and the seminiferous epithelium.

\section{Mechanism of action of TNF $\alpha$ in affecting BTB dynamics}

It seems that one of the primary targets of TNF $\alpha$ at the $\mathrm{BTB}$ is the $\mathrm{TJ}$ integral membrane proteins: occludin, claudin-11, and their adaptor ZO-1. For instance, studies using Sertoli cell cultures have shown that TNF $\alpha$ can inhibit claudin-11 (Hellani et al. 2000) and occludin (Siu et al. 2003a) production by Sertoli cells. A transient loss of these proteins plus cadherins at the BTB can likely render a temporal and spatial disruption of the BTB as illustrated by electron microscopy. Interestingly, JAM-A and catenins were not perturbed by TNF $\alpha$. Furthermore, a recent study has shown that catenins are crucial adaptors that cross-link the occludin/ZO-1 and the cadherin/catenin protein complexes at the BTB via the catenin-ZO-1 interaction to reinforce the BTB integrity (Yan \& Cheng 2005). It is plausible that the remaining JAM-A/ZO-1/catenin protein complex, which is largely unaffected by TNF $\alpha$, can temporarily safeguard the $\mathrm{BTB}$, such as its immunological barrier function and polarity function, while the occludin-ZO-1/cadherin-cadherin protein complex is transiently disrupted so as to facilitate germ cell migration. It is conceivable that another yet-to-be defined mechanism is in place at the BTB to perturb the JAM-A/ZO-1/catenin protein complex, which is working in concert with the occudin/ZO-1 and cadherin/catenin 
A
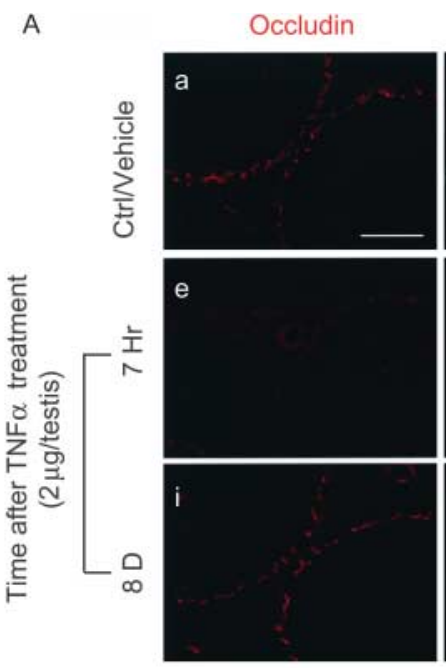

$\mathrm{N}$-Cadherin
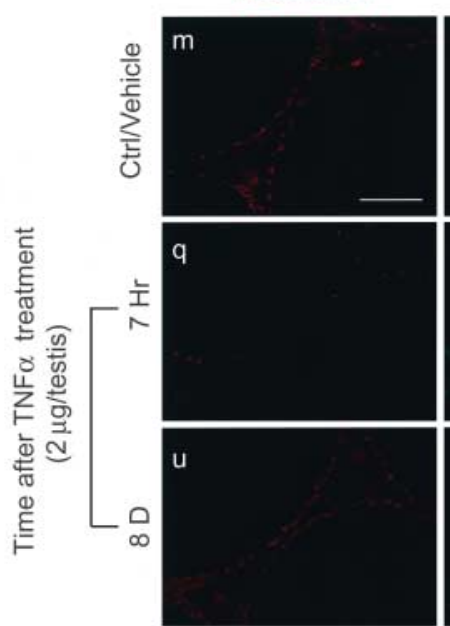

B

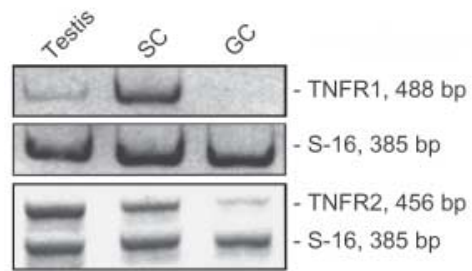

$\mathrm{ZO}-1$
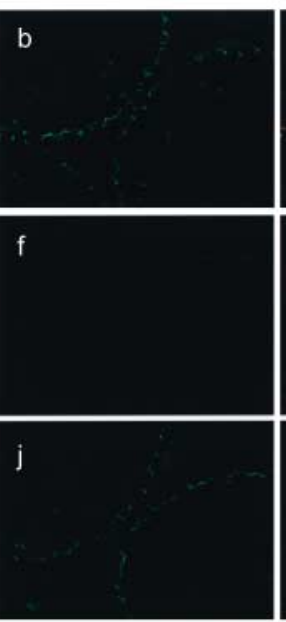

$\beta$-Catenin
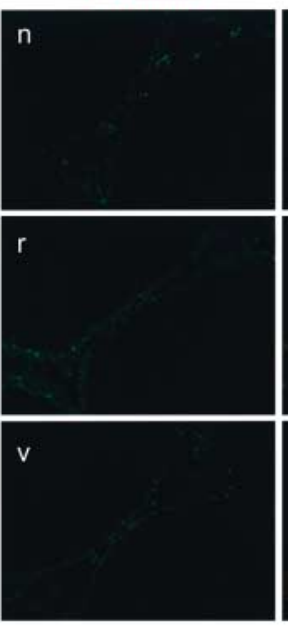

C
Merge
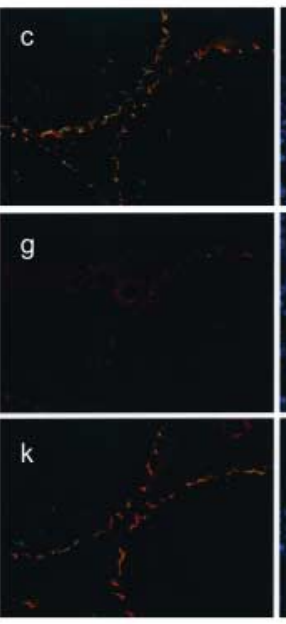

Merge
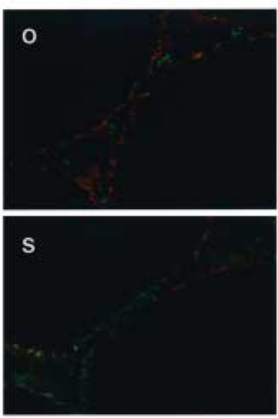

w
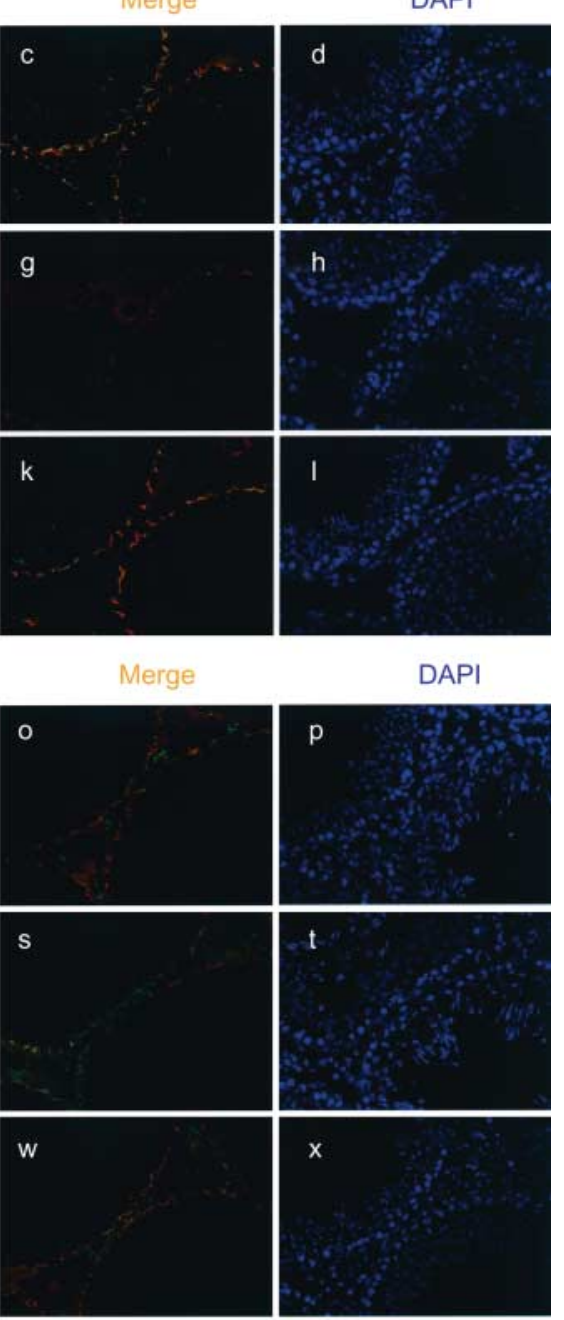

DAPI

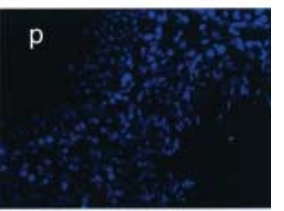
. 

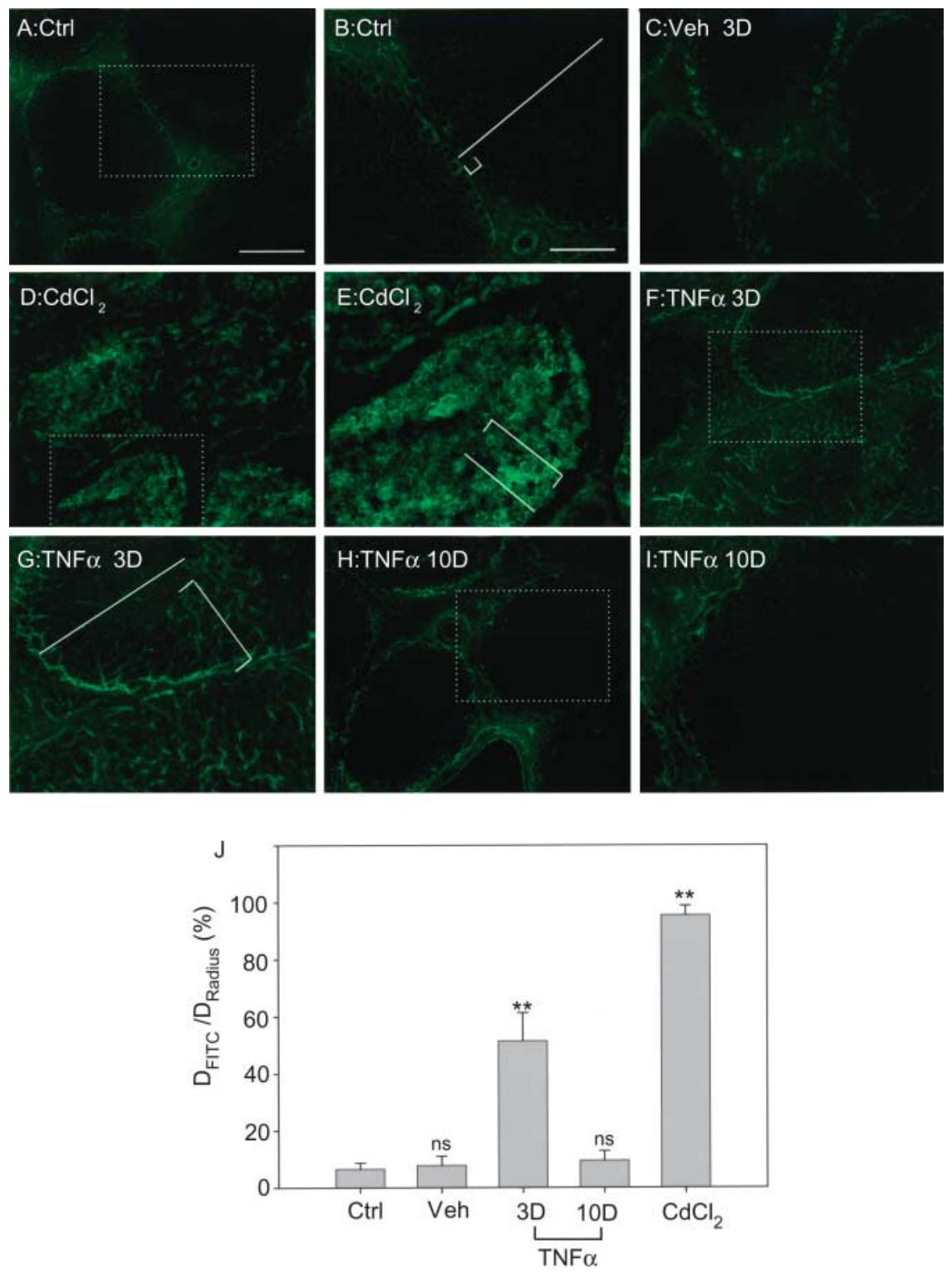

Figure 7 (A)-(J) A functional study to assess the BTB integrity following TNF $\alpha$ treatment in adult rats. Adult rats $(n=2$ for each time point in each treatment group; for controls, $n=3)$ were treated with either TNF $\alpha$ ( $2 \mu \mathrm{g} /$ testis via intratesticular injection; terminated on day 3 and 10$)$ or $\mathrm{CdCl}_{2}(3 \mathrm{mg} / \mathrm{kg}$ bw, i.p., terminated on day 5, positive control) and controls (normal testes, and testes treated with PBS terminated on day 3 ). The integrity of the BTB was then assessed by monitoring the diffusion of FITC across the barrier from the systemic circulation as shown in (A)-(C) (control groups) versus $\mathrm{CdCl}_{2}$ treatment (D)-(E) on day 5 (positive control), and TNF $\alpha$ treatment terminated on day $3(\mathrm{~F})-(\mathrm{G})$ and day $10(\mathrm{H})-(\mathrm{I})$. These analyses were summarized in $(\mathrm{J})$, which illustrates the distance of the FITC fluorescent staining from the basement membrane $\left(D_{\mathrm{FITC}}\right)$ (see white bracket in $(\mathrm{B}),(\mathrm{E})$, and $(\mathrm{G})$ ) versus the radius of a seminiferous tubule ( $\left.D_{\text {radius }}\right)$ as annotated by the white-line in (B), (E) and $(\mathrm{G})$. In control groups $(\mathrm{A})-(\mathrm{C})$, FITC was confined at or near the basement membrane. In the positive control group in which rats were treated with $\mathrm{CdCl}_{2}$ to disrupt the BTB for 5 days, FITC was found in the entire epithelium, and in the TNF $\alpha$-treated group, FITC was also detected in the epithelium away from the basement membrane by day $3(\mathrm{~F}),(\mathrm{G})$, but this FITC movement into the epithelium was not significantly different by day $10(\mathrm{H})$, (I) versus controls $((\mathrm{H})$, (I) vs $(\mathrm{A})-(\mathrm{C}))$. The boxed areas shown in $(A),(D),(F)$, and $(H)$ were magnified and shown in $(B),(E),(G)$, and (I) respectively. Bar in $A=60 \mu \mathrm{m}$, which applies to $(C),(D),(F)$, and $(H)$; bar in $B=60 \mu \mathrm{m}$, which applies to (E), (G), and (I). n.s., not significantly different by one-way ANOVA; ${ }^{* *} P<0 \cdot 01$. 

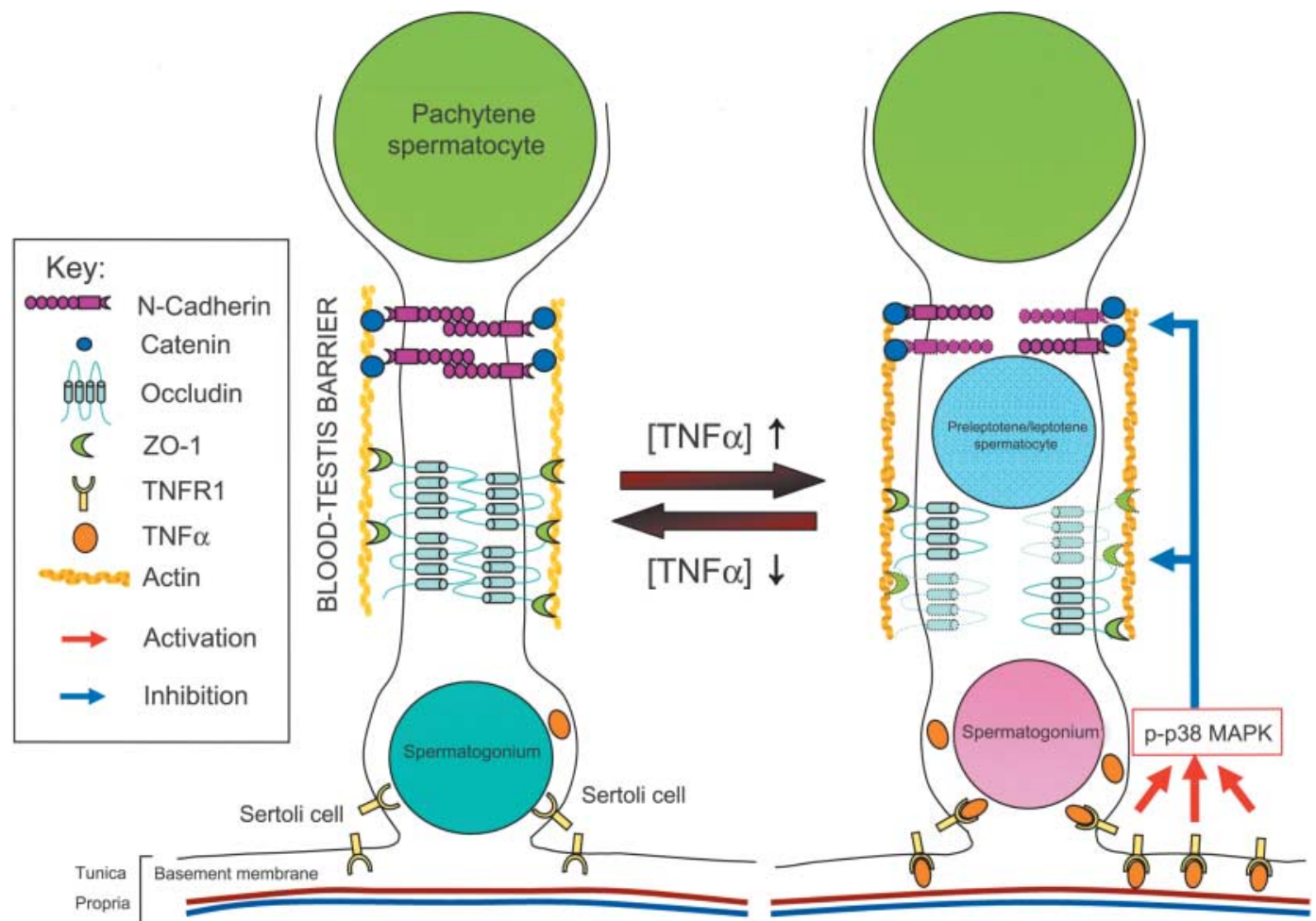

Figure 8 A schematic drawing illustrating the possible mechanism utilized by TNF $\alpha$ to reversibly perturb the BTB integrity facilitating germ cell migration. The left panel depicts the BTB at a 'closed' state when a relatively low level of TNF $\alpha$ is found in the microenvironment at stages other than VII and VIII. At late stages VII through VIII of the epithelial cycle, both Sertoli and germ cells release TNF $\alpha$ into the microenvironment (see right panel), this triggers an activation of p-38 MAPK. This, in turn, lowers the steady-state levels of occludins and cadherins (proteins in broken lines represent 'disintegrated' or 'internalized' BTB-integral membrane proteins), 'opening' the BTB to facilitate the migration of preleptotene and leptotene spermatocytes across the BTB while differentiating into pachytene spermatocytes. Thereafter, the production of TNF $\alpha$ by Sertoli and germ cells is reduced, favoring the 'closing' of the BTB at stages IX through early VII of the epithelial cycle.

protein complexes to regulate BTB dynamics. It is obvious that these events must be precisely coordinated via intriguing crosstalk between different protein complexes at the BTB, possibly kinases and phosphatases (Xia et al. 2005) as well as different cytoskeletons (Vogl 1989, Vogl et al. 1993, Green et al. 2005). Yet, there is another possible mechanism, which can also be utilized by TNF $\alpha$ to affect BTB dynamics. For instance, a recent study has shown that TNF $\alpha$ is capable of promoting the activation of pro-matrix metalloprotease-9 (MMP-9) to MMP-9 (the activated form of MMP-9) in Sertoli cells (Siu et al. 2003a), which is known to cleave type IV collagen (Collier et al. 1988). Since type IV collagen is a major component of the basement membrane in the seminiferous epithelium adjacent to the BTB (Dym 1994, Siu \& Cheng 2004), and that fragments of collagens are known to act as biologically active peptides, such as inducing disassembly of anchoring junctions (e.g. focal contacts) via their effects on focal adhesion kinase (Carragher et al. 1999); it is likely that TNF $\alpha$ can use this mechanism to regulate the steady-state level of type IV collagen in the basement membrane. The net result of such interactions can affect the BTB integrity, since a disruption of collagen function can perturb the Sertoli cell TJ-permeability barrier function (Siu et al. 2003a) and Sertoli-germ cell adhesion (Lustig et al. 1978), possibly by perturbing the scaffolding function of collagen in the basement membrane. Work is now in progress to investigate this possibility.

Additionally, a recent study has shown that TNF $\alpha$ also induces nitric oxide and inosine production by Sertoli cells, protecting these cells against hydrogen peroxide-induced damage via the ERK1/2 signaling pathway (Souza et al. 2005). Recent studies have also shown that nitric oxide regulates Sertoli cell TJ-barrier function via the cGMP/PKG signaling pathway (Lee \& Cheng 2003). Collectively, these data illustrate that $\mathrm{TNF} \alpha$ can exert its effects via multiple pathways to affect BTB dynamics and Sertoli-germ cell adhesion in the testis.

In summary, we have reported some interesting effects of TNF $\alpha$ in BTB dynamics in adult rat testes. TNF $\alpha$ is likely a key player in promoting transient disassembly of 
the BTB in vivo to facilitate the migration of preleptotene and leptotene spermatocytes across the barrier at stage VIII of the epithelial cycle. Furthermore, results of this study have also illustrated that local administration of $\mathrm{TNF} \alpha$ to adult rat testes to induce junction restructuring in the seminiferous epithelium can be an in vivo model to study BTB dynamics, since this cytokine is produced locally by Sertoli and germ cells in the testis, and its effects on the BTB and the seminiferous epithelium are reversible.

\section{Acknowledgements}

This work was supported in part by grants from the National Institutes of Health (NICHD, U01 HD045908 to C Y C; U54 HD029990 Project 3 to C Y C), CONRAD Program (CICCR CIG 01-72 to C Y C; CIG 01-74 to D D M), and Hong Kong Research Grant Council (HKU 7413/04M and HKU 7536/05M to W M L). M W M L studied as a summer intern in the C Y C Laboratory in New York, and was supported in part by a fellowship from the University of Hong Kong. Subsequent experiments were completed by W X, D D M, C Q F W and H H N Y. M K Y S performed most of the preliminary experiments in the $\mathrm{C} \mathrm{Y} \mathrm{C} \mathrm{Laboratory.} \mathrm{The}$ authors declare that there is no conflict of interest that would prejudice the impartiality of this scientific work.

\section{References}

Aggarwal BB 2003 Signalling pathways of the TNF superfamily: a doubleedged sword. Nature Reviews Immunology 3 745-756.

Besset V, Magueresse-Battistoni B, Colletee J \& Benahmed M 1996 Tumor necrosis factor $\alpha$ stimulates insulin-like growth factor binding protein 3 expression in cultured porcine Sertoli cells. Endocrinology 137 296-303.

Bornstein SR, Rutkowski H \& Vrezas I 2004 Cytokines and steroidogenesis. Molecular and Cellular Endocrinology 215 135-141.

Bradford MM 1976 A rapid and sensitive method for the quantitation of microgram quantities of protein utilizing the principle of protein-dye binding. Analytical Biochemistry 72 248-254.

Carragher NO, Levkau B, Ross R \& Raines EW 1999 Degraded collagen fragments promote rapid disassembly of smooth muscle focal adhesions that correlate with cleavage of $\mathrm{pp} 125^{\mathrm{FAK}}$, paxillin, and talin. Journal of Cell Biology 147 619-629.

Chan YL, Paz V, Olvera J \& Wool IG 1990 The primary structure of rat ribosomal protein S16. FEBS Letters 263 85-88.

Chung NP, Mruk D, Mo MY, Lee WM \& Cheng CY 2001 A 22-amino acid synthetic peptide corresponding to the second extracellular loop of rat occludin perturbs the blood-testis barrier and disrupts spermatogenesis reversibly in vivo. Biology of Reproduction 65 1340-1351.

Collier IE, Wilhelm SM, Eisen AZ, Marmer BL, Grant GA, Seltzer JL, Kronberger A, He CS, Bauer EA \& Goldberg GI 1988 H-Ras oncogene-transformed human bronchial epithelial cells (TBE-1) secrete a single metalloprotease capable of degrading basement membrane collagen. Journal of Biological Chemistry 263 6579-6587.

De SK, Chen HL, Pace JL, Hunt JS, Terranova PF \& Enders GC 1993 Expression of tumor necrosis factor- $\alpha$ in mouse spermatogenic cells. Endocrinology 133 389-396.
De Cesaris P, Starace D, Starace G, Filippini A, Stefanini M \& Ziparo E 1999 Activation of Jun $\mathrm{N}$-terminal kinase/stress-activated protein kinase pathway by tumor necrosis factor $\alpha$ leads to intercellular adhesion molecule-1 expression. The Journal of Biological Chemistry 274 28978-28982.

Dym M 1994 Basement membrane regulation of Sertoli cells. Endocrine Reviews 15 102-115.

Green KJ, Bohringer M, Gocken T \& Jones JCR 2005 Intermediate filament associated proteins. Advances in Protein Chemistry 70 143-202.

Hedger MP 2002 Macrophages and the immune responsiveness of the testis. American Journal of Reproductive Immunology 57 19-34.

Hedger MP \& Meinhardt A 2003 Cytokines and the immune-testicular axis. Journal of Reproductive Immunology 58 1-26.

Hellani A, Ji JW, Mauduit C, Deschildre C, Tabone E \& Benahmed M 2000 Developmental and hormonal regulation of the expression of oligodendrocyte-specific protein/claudin 11 in mouse testis. Endocrinology 141 3012-3019.

Hew KW, Heath GL, Jiwa AH \& Welsh MJ 1993 Cadmium in vivo causes disruption of tight junction-associated microfilaments in rat Sertoli cells. Biology of Reproduction 49 840-849.

Hong CY, Park JH, Ahn RS, Im SY, Choi HS, Soh J, Mellon SH \& Lee K 2004 Molecular mechanism of suppression of testicular steroidogenesis by proinflammatory cytokine tumor necrosis factor $\alpha$. Molecular and Cellular Biology 24 2593-2604.

Lee NPY \& Cheng CY 2003 Regulation of Sertoli cell tight junction dynamics in the rat testis via the nitric oxide synthase/soluble guanylate cyclase $/ 3^{\prime}, 5^{\prime}$-cyclic guanosine monophosphate/protein kinase G signaling pathway: an in vitro study. Endocrinology 144 3114-3129.

Lui WY, Lee WM \& Cheng CY 2003a Transforming growth factor- $\beta 3$ regulates the dynamics of Sertoli cell tight junctions via the p38 mitogen-activated protein kinase pathway. Biology of Reproduction 68 1597-1612.

Lui WY, Wong CH, Mruk DD \& Cheng CY $2003 b$ TGF- $\beta 3$ regulates the blood-testis barrier dynamics via the p38 mitogen activated protein (MAP) kinase pathway: an in vivo study. Endocrinology 144 1139-1142.

Lustig L, Denduchis B, Gonzalez NN \& Puig RP 1978 Experimental orchitis induced in rats by passive transfer of an antiserum to seminiferous tubule basement membrane. Archives of Andrology $1333-343$.

Magueresse-Battistoni B, Morera AM \& Benahmed M 1995 In vitro regulation of rat Sertoli cell inhibin messenger RNA levels by transforming growth factor- $\beta 1$ and tumor necrosis factor $\alpha$. Journal of Emergency Medicine 146 501-508.

Mankertz J, Tavaladi S, Schmitz H, Mankertz A, Riecken EO, Fromm M \& Schulzke JD 2000 Expression from the human occludin promoter is affected by tumor necrosis factor- $\alpha$ and interferon- $\gamma$. Journal of Cell Science 113 2085-2090.

Mauduit C, Jaspar JM, Poncelet E, Charlet C, Revol A, Franchimont P \& Benahmed M 1993 Tumor necrosis factor- $\alpha$ antagonizes folliclestimulating hormone action in cultured Sertoli cells. Endocrinology 133 69-76.

Mealy K, Robinson B, Millette CF, Majzoub J \& Wilmore DW 1990 The testicular effects of tumor necrosis factor. Annals of Surgery 211 470-475.

Mruk DD \& Cheng CY 2004 Sertoli-Sertoli and Sertoli-germ cell interactions and their significance in germ cell movement in the seminiferous epithelium during spermatogenesis. Endocrine Reviews $\mathbf{2 5}$ 747-806.

Nehar D, Mauduit C, Boussouar F \& Benahmed M 1997 Tumor necrosis factor- $\alpha$-stimulated lactate production is linked to lactate dehydrogenase a expression and activity increase in porcine cultured Sertoli cells. Endocrinology 138 1964-1971.

Pentikainen V, Erkkila K, Suomalainen L, Otala M, Pentikainen MO, Parvinen M \& Dunkel L 2001 TNF- $\alpha$ down-regulated the Fas ligand and inhibits germ cell apoptosis in the human testis. Journal of Clinical Endocrinology and Metabolism 86 4480-4488.

Russell LD 1977 Movement of spermatocytes from the basal to the adluminal compartment of the rat testis. American Journal of Anatomy 148 313-328.

Russell LD 1993 Morphological and Functional Evidence for Sertoli-Germ Cell Relationships. In The Sertoli Cell, pp 365-390. Eds L Russell \& M Griswold. St. Louis, MO, USA: Cache River Press. 
Russell LD \& Peterson RN 1985 Sertoli cell junctions: morphological and functional correlates. International Review of Cytology 94 177-211.

Russell LD, Saxena NK \& Weber JE 1987 Intratesticular injection as a method to assess the potential toxicity of various agents to study mechanisms of normal spermatogenesis. Gamete Research 17 43-56.

Setchell BP \& Waites GMH 1970 Changes in the permeability of the testicular capillaries and of the 'blood-testis barrier' after injection of cadmium chloride in the rat. Journal of Endocrinology 47 81-86.

Sigillo F, Guillou F, Benahmed M \& Magueresse-Battistoni BL 1999 In vivo regulation of rat Sertoli cell transferrin expression by tumor necrosis factor $\alpha$ and retinoic acid. Molecular and Cellular Endocrinology 148 163-170.

Siu MKY \& Cheng CY 2004 Dynamic cross-talk between cells and the extracellular matrix in the testis. BioEssays 26 978-992.

Siu MKY, Lee WM \& Cheng CY 2003a The interplay of collagen IV, tumor necrosis factor- $\alpha$, gelatinase B (matrix metalloprotease-9), and tissue inhibitor of metalloprotease-1 in the basal lamina regulates Sertoli cell-tight junction dynamics in the rat testis. Endocrinology 144 371-387.

Siu MKY, Mruk DD, Lee WM \& Cheng CY $2003 b$ Adhering junction dynamics in the testis are regulated by an interplay of $\beta 1$-integrin and focal adhesion complex (FAC)-associated proteins. Endocrinology 144 21412163.

Siu MKY, Wong CH, Lee WM \& Cheng CY 2005 Sertoli-germ cell anchoring junction dynamics in the testis are regulated by an interplay of lipid and protein kinases. Journal of Biological Chemistry 280 25029-25047.

Skinner MK 1993 Secretion of growth factors and other regulatory factors. In The Sertoli Cell, pp 237-247. Eds L Russell \& M Griswold. St. Louis, MO, USA: Cache River Press.

Souza LF, Horn AP, Gelain DP, Jardim FR, Lenz G \& Bernard EA 2005 Extracellular inosine modulates ERK1/2 and p38 phosphorylation in cultured Sertoli cells: possible participation in TNF- $\alpha$ modulation of ERK 1/2. Life Sciences 77 3117-3126.

Suescun MO, Rival C, Theas MS, Calandra RS \& Lustig L 2003 Involvement of tumor necrosis factor- $\alpha$ in the pathogenesis of autoimmune orchitis in rats. Biology of Reproduction 68 2114-2122.

Suominen JS, Wang Y, Kaipia A \& Toppari J 2004 Tumor necrosis factor- $\alpha$ $(\mathrm{TNF}-\alpha)$ promotes cell survival during spermatogenesis, and this effect can be blocked by infliximab, a TNF- $\alpha$ antagonist. European Journal of Endocrinology 151 629-640.

Tabibzadeh T, Kong QF, Kapur S, Satyaswaroop PG \& Aktories K 1995 Tumor necrosis factor- $\boldsymbol{\alpha}$-mediated dyscohesion of epithelial cells associated with disordered expression of cadherin/ $\beta$-catenin and disassembly of actin filaments. Human Reproduction 10 99-104.

Vilcek J 2003 The cytokines: an overview. In The Cytokine Handbook, pp 3-18. Eds AW Thomson \& MT Lotze. New York, NY, USA: Academic Press.

Vogl AW 1989 Distribution and function of organized concentrations of actin filaments in mammalian spermatogenic cells and Sertoli cells. International Review of Cytology 119 1-56.

Vogl AW, Pfeiffer DC, Redenbach DM \& Grove BD 1993 Sertoli cell cytoskeleton. In The Sertoli Cell, pp 39-86. Eds L Russell \& M Griswold. St Louis, MO, USA: Cache River Press.

Wiebe JP, Barr KJ, Buckingham KD, Gedded PD \& Kudo PA 1986 Prospects of a male contraceptive based on selective antispermatogenic action of 1,2,3-trihydroxypropane (THP; glycerol). In Male Contraception: Advances and Future Prospects, 3, pp 252-270. Eds G Zatuchni, A Goldsmith, A Spiler \& J Sciarra. PA, USA: Harper and Row.

Wiebe JP, Kowalik A, Gallardi RL, Egeler O \& Clubb BH 2000 Glycerol disrupts tight junction-associated actin microfilaments, occludin, and microtubules in Sertoli cells. Journal of Andrology 21 625-635.

Wong CH, Mruk DD, Lui WY \& Cheng CY 2004 Regulation of blood-testis barrier dynamics: an in vivo study. Journal of Cell Science 117 783-798.

Wong CH, Mruk DD, Siu MKY \& Cheng CY 2005 Blood-testis barrier dynamics are regulated by $\alpha_{2}$-macroglobulin via the c-Jun $\mathrm{N}$-terminal protein kinase pathway. Endocrinology 146 1893-1908.

Xia W \& Cheng CY 2005 TGF- $\beta 3$ regulates anchoring junction dynamics in the seminiferous epithelium of the rat testis via the Ras/ERK signaling pathway: an in vivo study. Developmental Biology 280 321-343.

Xia W, Mruk DD, Lee WM \& Cheng CY 2005 Cytokines and junction restructuring during spermatogenesis-a lesson to learn from the testis. Cytokine and Growth Factor Reviews 16 469-493.

Yan HHN \& Cheng CY 2005 Blood-testis barrier dynamics are regulated by an engagement/disengagement mechanism between tight and adherens junctions via peripheral adaptors. PNAS 102 11722-11727.

Received 1 February 2006

Received in final form 21 April 2006

Accepted 11 May 2006

Made available online as an Accepted Preprint 29

May 2006 